DOSSIÊ

\title{
A produção do conhecimento na licenciatura em Educação do Campo: desafios e possibilidades para o fortalecimento da educação do campo
}

\author{
Mônica Castagna Molina' \\ Maria Isabel Antunes-Rocha" \\ Maria de Fátima Almeida Martins"

\section{RESUMO}

Este texto objetiva discutir a produção do conhecimento no âmbito das licenciaturas em Educação do Campo buscando compreender sua contribuição para ampliar e fortalecer os princípios, conceitos e práticas articulados pelo Movimento da Educação do Campo. Os dados foram obtidos no Banco de Dissertações e Teses da Coordenação de Aperfeiçoamento de Pessoal de Nível Superior (Capes), na Plataforma de Grupos de Pesquisa do Conselho Nacional de Desenvolvimento Científico e Tecnológico $(\mathrm{CNPq})$ e em trabalhos acadêmicos já publicados. $\mathrm{O}$ conjunto da produção indica a presença de pesquisas desenvolvidas em todas as regiões do país, abordando temáticas que tratam tanto das especificidades da formação docente ofertada por esses cursos aos sujeitos camponeses quanto de questões relacionadas à formação e prática docente como um todo. Para concluir, demonstra-se que esse formato vem contribuindo para o diálogo entre a educação pública sem perder a especificidade demandada pela educação do campo.

\section{PALAVRAS-CHAVE}

produção do conhecimento; educação do campo; licenciatura em Educação do Campo; educação pública. 


\title{
KNOWLEDGE PRODUCTION IN THE DEGREE COURSE OF EDUCATION FOR RURAL AREAS: CHALLENGES AND POSSIBILITIES FOR STRENGTHENING EDUCATION FOR RURAL AREAS
}

\begin{abstract}
This text aims at discussing the production of knowledge in degree courses of Education for Rural Areas, seeking to understand its contribution to expand and strengthen the principles, concepts and practices articulated by the Movement for Education for Rural Areas. Data were obtained from the Dissertation and Thesis Bank of the Coordination of High-level Staff Qualifying (Capes), Research Groups Platform of the National Counsel for Scientific and Technological Development $(\mathrm{CNPq})$ and from published academic papers. The set of production indicates the presence of research carried out in all regions of the country, addressing themes that deal with both the specificities of teacher qualification offered by these courses to rural laborers, as well as issues related to teacher qualification and practice in a generic sense. To conclude, it is demonstrated that this format has been contributing to the dialogue between public education without losing the specificities demanded by the education for rural areas.
\end{abstract}

\section{KEYWORDS}

knowledge production; education for rural areas; degree course on Education for Rural Areas; public education.

\section{PRODUCCIÓN DE CONOCIMIENTOS EN LOS GRADOS DE EDUCACIÓN EN ÁREAS RURALES: DESAFIOS Y POSIBILIDADES PARA FORTALECER LA EDUCACIÓN EN ÁREAS RURALES}

\section{RESUMEN}

Este texto tiene como objetivo discutir la producción de conocimiento en materia de los grados en Educación en Áreas Rurales, buscando comprender su contribución para expandir y fortalecer los principios, conceptos y prácticas articulados por el Movimiento de Educación en Áreas Rurales. Los datos se obtuvieron del Banco de Tesis de maestría y doctorado de la Coordinación de Perfeccionamiento de Personal de Alto Nivel (Capes), la Plataforma de Grupos de Investigación del Consejo Nacional de Investigación Científica y Tecnológica (CNPq) y de trabajos académicos publicados. El conjunto de producción indica la presencia de investigaciones llevadas a cabo en todas las regiones del país, que abordan temas que tratan tanto las especificidades de la formación del profesorado que ofrecen estos cursos a los trabajadores rurales, como también cuestiones relacionadas con la educación y la práctica docente en general. Para concluir, se demuestra que este formato ha contribuido al diálogo entre la educación pública sin perder la especificidad exigida por la educación rural.

\section{PALABRAS CLAVE}

producción de conocimiento; educación en áreas rurales; grado en Educación para Áreas Rurales; educación pública. 


\section{INTRODUÇÃO}

Este texto objetiva discutir a produção do conhecimento acadêmico (Catani e Oliveira, 2015; Torriglia e Duarte, 2019) desenvolvida no contexto dos cursos de licenciatura em Educação do Campo (LEC) no Brasil. As LECs surgiram no âmbito das lutas do Movimento da Educação do Campo e, nessa trajetória, são uma das principais ações na esfera das políticas públicas. Considerou-se relevante proceder a este estudo tendo em vista a compreensão da produção acadêmica como importante fator no processo de fortalecimento da educação do campo no tocante ao resultado das lutas e das conquistas dos camponeses.

Para nos referirmos aos povos camponeses neste artigo, faz-se necessária uma breve reflexão sobre como esses sujeitos concretizam seus modos de vida nos respectivos territórios. Costa e Carvalho (2012) postulam que o campesinato é compreendido por suas relações com a terra, sendo esta a base de sua existência e lugar para a satisfação das necessidades de cada unidade de produção familiar camponesa. Seja coletiva, seja isoladamente, as famílias camponesas realizam suas atividades e preparam seus planos, fazendo corresponder os frutos de seu trabalho às necessidades da manutenção e/ou reprodução do modo de vida camponês, expressando-os territorialmente. No campesinato é importante destacar que a família constitui a unidade para a realização do trabalho e garantia de sua existência. $\mathrm{Ou}$ seja, "o caráter familiar da produção tem sido visto como a pedra de toque para a compreensão do campesinato" (Woortmann, 2014, p. 229).

A educação do campo consiste num conjunto de práticas, princípios e políticas que vêm sendo formuladas desde o fim dos anos 1990 por sujeitos envolvidos na construção de um projeto de escola articulado a um de campo e de sociedade. As organizações coletivas dos povos camponeses foram os principais construtores dessa proposta, tendo em vista que partiu deles a mobilização e a criação do que acabou sendo denominado de Movimento da Educação do Campo. Nessa trajetória foram elaboradas políticas públicas, instauradas práticas educativas em diferentes níveis e modalidades de ensino, desenvolvidos centenas de projetos, e, paralelamente a essa variada gama de ações, foi constituído um consistente processo de produção de conhecimento acadêmico em todas as regiões do país. Ao longo dos últimos 20 anos, os estudos vêm apontando efetivas alterações em práticas escolares, na formação e prática docentes e na trajetória socioprofissional dos egressos e das comunidades que desenvolvem projetos educacionais vinculados a essa perspectiva (Freitas, 2019; Carvalho, 2018; Esmeraldo, Molina e Antunes-Rocha, 2017).

A produção do conhecimento na educação do campo tem sido desenvolvida majoritária, mas não exclusivamente, como uma ação que ocorre nas, com as e por meio das práticas sociais protagonizadas por seus sujeitos, ligada aos contextos territoriais nos quais se produz sua vida material. Parte significativa do processo de produção do conhecimento na educação do campo tem sido feita pelos próprios sujeitos participantes dos cursos apoiados pelas políticas públicas conquistadas em seu âmbito, tais como as desenvolvidas pelo Programa Nacional de Educação na Reforma Agrária (Pronera) e pelo Programa de Apoio à Formação Superior em LEC (Procampo) (Molina e Antunes-Rocha, 2014). 
Dados os princípios originários do Movimento da Educação do Campo e de sua intrínseca vinculação com a luta de classes, entende-se que há elementos presentes na concepção dessas políticas que efetivamente têm contribuído para promover uma formação crítica e transformadora. Trata-se de uma formação que, em vez de formar educadores do campo como intelectuais da disseminação da nova pedagogia da hegemonia (Neves, 2013), forma educadores formuladores e disseminadores da contra-hegemonia como sujeitos sócio-históricos capazes de compreender e promover a necessária articulação das lutas entre as escolas do campo e a superação dos elementos que sustentam a estrutura da sociedade capitalista (Molina e Hage, 2015).

$\mathrm{Na}$ última década, as reflexões sobre a produção do conhecimento na educação do campo ampliaram-se e desencadearam um significativo debate, perpassando diferentes dimensões desse processo com ênfase nas questões epistemológicas, gnosiológicas e ontológicas nele envolvidas (Souza, 2008, 2015; Albuquerque, 2013; Lima, 2017; Ghedini, 2017). As reflexões acerca da temática passaram a ser objeto de diferentes trabalhos na pesquisa em educação do campo tanto no âmbito nacional (Almeida e Chamon, 2012; Gonçalves e Hayashi, 2016) quanto no regional (Medeiros e Dias, 2015; Senra e Sato, 2012). Tal como apontam Romanowski e Ens (2006), esses tipos de pesquisa são importantes porque possibilitam a efetivação de um balanço da investigação de determinada área do conhecimento. Considerando a novidade da educação do campo como tal e o curto tempo de sua existência em termos históricos, com seus 20 anos de existência recém-completados em 2018, não deixa de ser significativo o fato de já existirem diversos trabalhos de estado da arte sobre ela, o que por si só já indica a riqueza de produções que ela tem sido capaz de gerar em função da imensa diversidade de práticas realizadas com base na compreensão da tal orientação formativa.

As informações utilizadas neste artigo foram obtidas em três fontes mediante o uso dos seguintes descritores: Educação do Campo, Licenciatura em Educação do Campo e Procampo. No primeiro, buscou-se em trabalhos já publicados dados da produção científica. No segundo, acessou-se o Banco de Teses e Dissertações da Coordenação de Aperfeiçoamento de Pessoal de Nível Superior (Capes). A plataforma do Conselho Nacional de Desenvolvimento Científico e Tecnológico $(\mathrm{CNPq})$ constituiu a terceira fonte por meio da qual foi pesquisado o registro de núcleos de estudos e pesquisas.

Para promover esta reflexão, o artigo estrutura-se em quatro partes. Inicialmente, apresenta-se a compreensão da educação do campo e da produção do conhecimento que ela advoga. No segundo momento, julgou-se ser necessário apresentar dados relativos à produção do conhecimento gerado pelo Pronera, por se considerar que esse programa não só constitui uma das referências para entender a educação do campo no Brasil, mas também porque sem seu acúmulo na oferta das experiências de pedagogia da terra não haveria a LEC. O intenso desenvolvimento das experiências do Pronera pelas instituições de ensino superior traduz-se no avanço e no enraizamento dessa área de estudo por intermédio da criação de núcleos de pesquisa e da ampliação da publicação de artigos sobre a temática, como se verá no tópico a seguir. $\mathrm{Na}$ sequência, apresentam-se dados quanto à produção 
do conhecimento dos cursos de LEC oriundos de teses e dissertações produzidas. Para concluir, sistematiza-se uma reflexão a respeito dos desafios e das possibilidades dessa nova modalidade de formação docente como um território de produção do conhecimento diante da tarefa de fortalecer e expandir a educação do campo como movimento de luta e território de práticas vinculadas aos direitos demandados pelos povos camponeses.

\section{A CONCEPÇÃO DA PRODUÇÃO DO CONHECIMENTO NA EDUCAÇÃO DO CAMPO}

Inicia-se este tópico partindo da compreensão expressa por Frigotto (2008) em relação aos processos de produção do conhecimento:

A produção e a divulgação do conhecimento não se faz alheia aos conflitos, antagonismos e relações de força que se estabelecem entre as classes ou grupos sociais. A produção do conhecimento é ela mesma parte e expressão dessa luta. Neste sentido que a teoria se constitui em força material e a consciência crítica um elemento fundamental e imprescindível na luta pela transformação das relações sociais marcadas pela alienação e exclusão. Evidencia-se aqui, também, de forma mais clara, porque a pretensão positivista da neutralidade do conhecimento social, sob as condições de uma sociedade fraturada, cindida historicamente, é inviável. Esta visão de neutralidade, ao contrário, expressa apenas a representação do tipo de consciência e de conhecimento funcional a reprodução das relações sociais dominantes. (Frigotto, 2008, p. 51)

A produção do conhecimento na educação do campo, objeto deste artigo, vincula-se à compreensão de que o conhecimento científico também é um produto histórico e social inserido na sociedade capitalista contemporânea e marcado pelos intensos conflitos nela presentes. Essa concepção educativa materializa-se pela luta de classes no campo brasileiro, colocando-se como parte e ao lado do polo do trabalho, assumindo e defendendo a educação como um direito e um bem público e social. A produção do conhecimento na perspectiva do materialismo histórico dialético faz sentido em sua articulação com o conjunto da totalidade histórica e social. Segundo Frigotto (2008), as ideias e as concepções não têm vida própria, elas expressam o momento histórico e a forma de organização do modo de produzir a vida material do ser humano em cada tempo e espaço histórico. A fragmentação do conhecimento tem sua origem na divisão social que surge com a propriedade privada. $\mathrm{Na}$ sociedade capitalista moderna, essa fragmentação assume discursos e práticas que contribuem para aprofundar a distância entre a produção e a reprodução material da vida e entre a produção e a reprodução de conhecimentos.

A educação do campo encontra-se desafiada como um território produtor de conhecimentos, entendendo essa prática como transformadora e comprometida com a superação da exploração do trabalho e da natureza na perspectiva da acumulação capitalista. Assumir a totalidade social com suas contradições como referência 
para uma atividade teórica que se pretende emancipadora passa possivelmente pela apropriação de um conhecimento que permita compreender a origem, a natureza e a função social dos conhecimentos e das formas de conhecer que são hegemônicas na atualidade, produzindo, ao mesmo tempo, novos conteúdos, novas metodologias e novas intencionalidades para os resultados a serem obtidos.

As práticas da educação do campo avançam na direção de mostrar os caminhos pelos quais tem sido possível a defesa de uma produção de conhecimento baseada na relação direta entre o conhecimento científico e a sabedoria dos povos do campo mediante o diálogo de saberes (Toná, 2008). Nesse diálogo, são imprescindíveis a problematização da realidade e a revalorização dos conhecimentos sociais dos camponeses, buscando articular a essa valorização a geração e a disseminação de tecnologias que sejam adequadas à diversidade dos territórios nos quais se encontram os sujeitos em formação, em prol da transformação da realidade social das famílias camponesas.

\section{MATERIALIDADES E TERRITORIALIDADES DA PRODUÇÃO DO CONHECIMENTO NA EDUCAÇÃO DO CAMPO}

Com o apoio do Pronera, foram realizados no período de 1998 a 2011 cerca de 320 cursos vinculados às concepções da educação do campo nas áreas de educação de jovens e adultos, ensino médio e ensino superior, envolvendo 82 instituições de ensino e 38 organizações sociais, com a participação de 161.894 educandos em diferentes regiões do país. No âmbito da graduação (Pedagogia da Terra, Pedagogia das Águas, História, Letras, Artes, Geografia, Direito, Agronomia etc.), o programa contabiliza um total de 5.920 produções no período mencionado (produções em vídeos, apostilas, textos, músicas, artigos).

Os dados levantados pela II Pesquisa Nacional sobre a Educação na Reforma Agrária (II PNERA) apontaram que, de maneira geral, para cada um dos cursos ofertados há diferentes processos de produção do conhecimento acadêmico em monografias, dissertações ou teses. No mapa da Figura 1, é possível ter uma ideia da espacialidade em termos de municípios onde os cursos foram ofertados (Ipea, 2015).

$\mathrm{Da}$ Figura 2 constam os indicadores de produção sobre esses cursos. No período da pesquisa, foram registradas 260 dissertações de mestrado, 63 teses de doutorado e 174 monografias sobre o Pronera, além de 51 livros, 10 coletâneas, 94 capítulos de livros e 469 artigos. Os pesquisadores também registraram 40 vídeos e documentários, 35 periódicos e 78 eventos, dados que mostram a pujança de produções do Pronera.

A educação do campo também se materializa na criação de grupos de pesquisa nas universidades e na publicação de artigos em periódicos. Foi identificada a existência de 285 grupos de pesquisa registrados na plataforma do CNPq. Observa-se na Figura 3 que esses grupos estão presentes em todas as regiões brasileiras e em maior número na Região Nordeste. Numa análise mais refinada dos dados da plataforma, constata-se que os núcleos de pesquisa estão funcionando em 127 instituições de educação superior, sendo 120 públicas (federais e estaduais) e sete de natureza privada. Os dados levantados indicam que a educação do campo está sendo tema de pesquisa em todas as regiões brasileiras, com base na sua presença em um expressivo contingente de instituições de educação superior. 


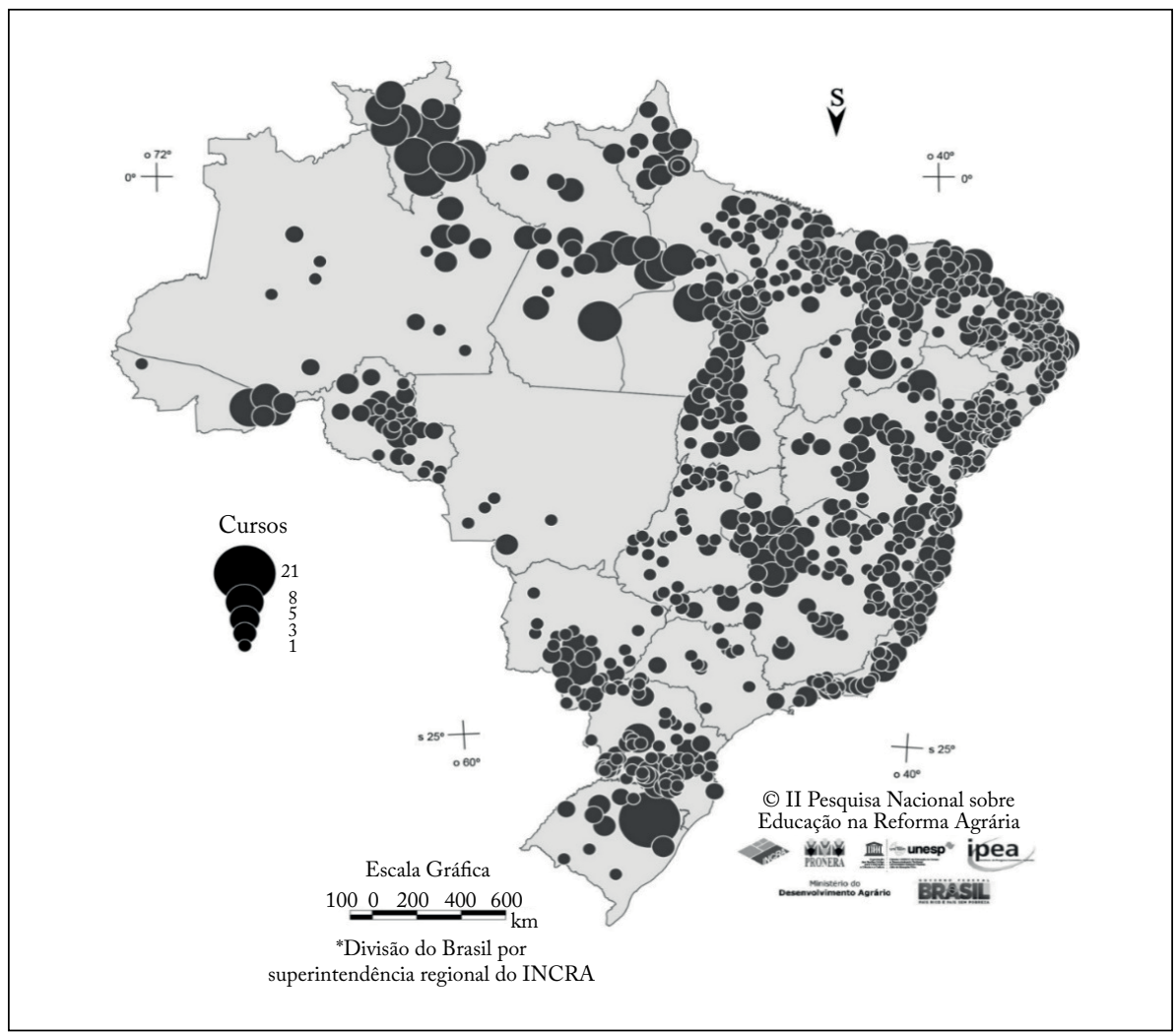

Figura 1 - Cursos do Programa Nacional de Educação na Reforma Agrária (Pronera) por município de realização (1998-2011).

Fonte: Ipea (2015).

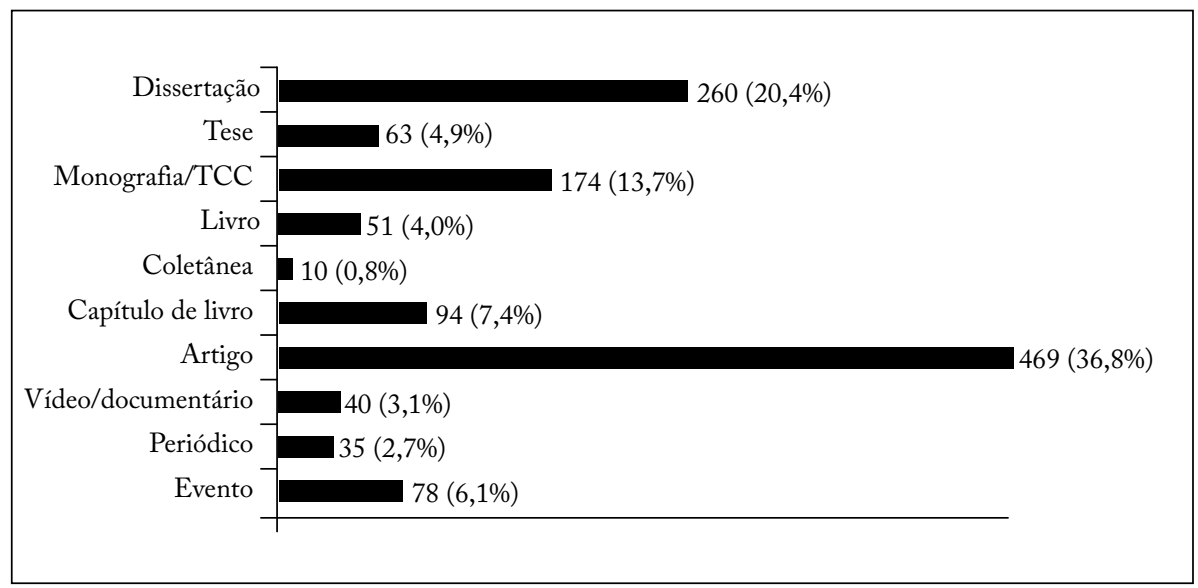

Figura 2 - Produções sobre o Programa Nacional de Educação na Reforma Agrária (Pronera) (1998-2011).

TCC: trabalho de conclusão de curso.

Fonte: Ipea (2015). 


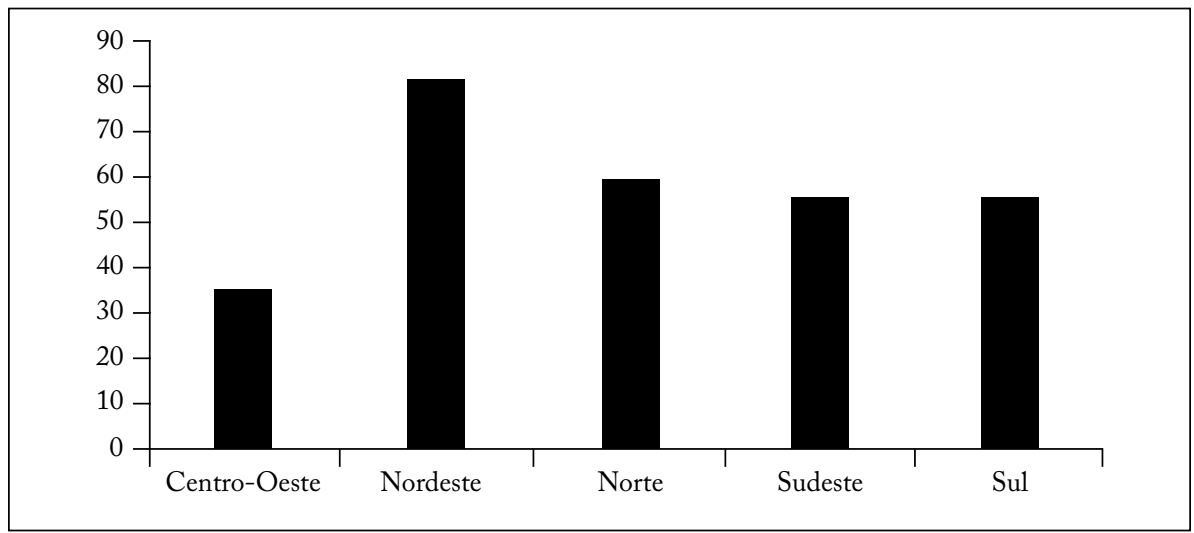

Figura 3 - Distribuição de grupos de pesquisa por regiões, Brasil ( $\mathbf{n}=285)$.

Fonte: adaptado do banco de dados de CNPq (2019).

No Banco de Dissertações e Teses da Capes (apud Carvalho, 2018), verifica-se o total de 451 produções referentes ao descritor educação do campo no período de 15 anos. Nessa produção estão envolvidas 17 instituições distribuídas em todas as regiões do país. No levantamento elaborado por Carvalho (2018), compreendendo o período de 2001 a 2016, a Figura 4 evidencia a crescente ampliação da produção de artigos. Se relacionados aos números de núcleos de pesquisa e de dissertações e teses concluídas, os índices encontrados revelam considerável produção e divulgação de conhecimentos a partir de 2010, também com base nos resultados relativos a projetos de ensino e extensão.

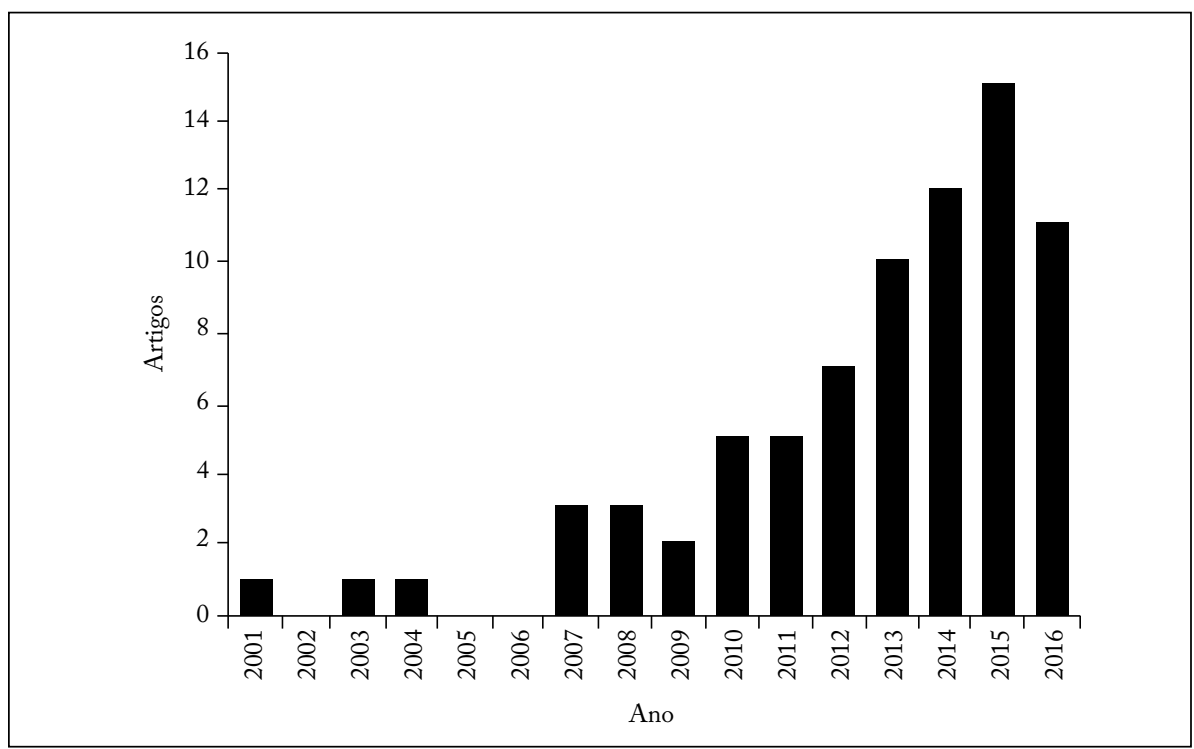

Figura 4 - Publicação de artigos em periódicos indexados na plataforma Biblioteca Eletrônica Científica Online (SciELO) (2001-2016).

Fonte: Carvalho (2018, p. 59). 
No mesmo levantamento, Carvalho (2018) ressalva as publicações por periódicos classificados como A no Qualis Periódicos com a temática da educação do campo. Na Figura 5 é possível ver a denominação e a qualificação dos periódicos. Aqui vale ressaltar as publicações em periódicos classificados como $C$, não computados neste trabalho, mas que constituem significativo volume de produção, notadamente no que diz respeito à divulgação dos resultados de pesquisas produzidas em cursos de especialização e trabalhos em que são apresentados resultados de experiências.

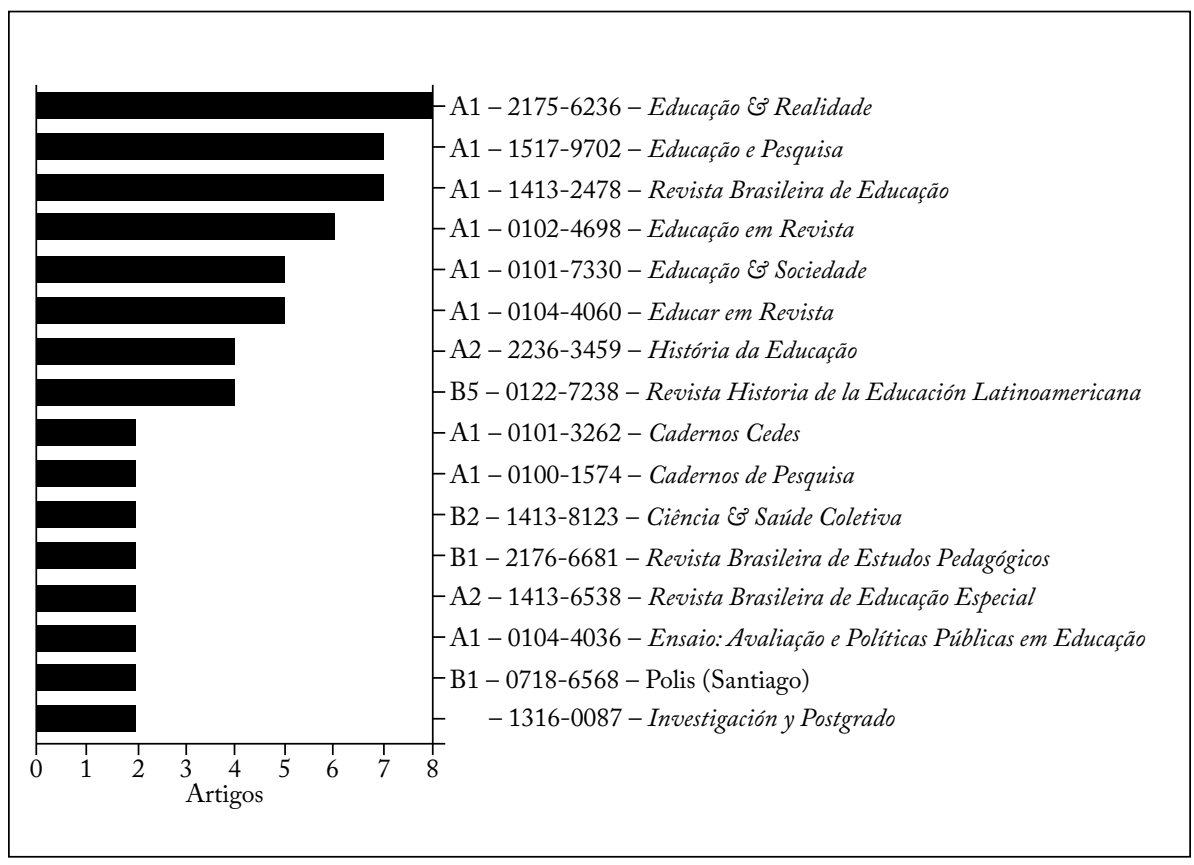

Figura 5 - Publicação de artigos por periódicos (2001-2016).

Fonte: Carvalho (2018, p. 57).

\section{PRODUÇÃO DO CONHECIMENTO NOS CURSOS DE LICENCIATURA EM EDUCAÇÃO DO CAMPO}

Os cursos de LEC foram criados por meio da oferta já disponibilizada pela Universidade Federal de Minas Gerais (UFMG) com apoio do Pronera de 2005 em diante (Antunes-Rocha e Martins, 2009; Antunes-Rocha, 2010). Em 2007 o Ministério da Educação (MEC) convidou universidades para desenvolverem experiências piloto do curso em quatro instituições - Universidade de Brasília (UnB), UFMG, Universidade Federal de Sergipe (UFS) e Universidade Federal da Bahia (UFBA) -, objetivando, com elas, criar o Procampo. As reflexões e análises sobre tais experiências, bem como o projeto político-pedagógico que orientou a formatação final dessa proposta de formação docente, estão assinaladas em Molina e Sá (2011) e Molina (2014). Após essas experiências, o MEC lançou edital (2009) para que mais universidades 
pudessem ofertar a licenciatura, porém como projeto especial de turmas únicas. Em 2012, em razão da pressão dos movimentos sociais e sindicais, foram conquistados 44 cursos permanentes dessa nova graduação em todas as regiões do país. Objetivando garantir a implementação dos cursos, o MEC disponibilizou 600 vagas de concurso público de docentes da educação superior e 126 vagas de técnicos como suporte para esse processo (Molina, 2017). Na atualidade estão em execução 44 cursos de LEC, distribuídos em 31 universidades e quatro institutos federais, com presença em todas regiões brasileiras, conforme o mapa da Figura 6.

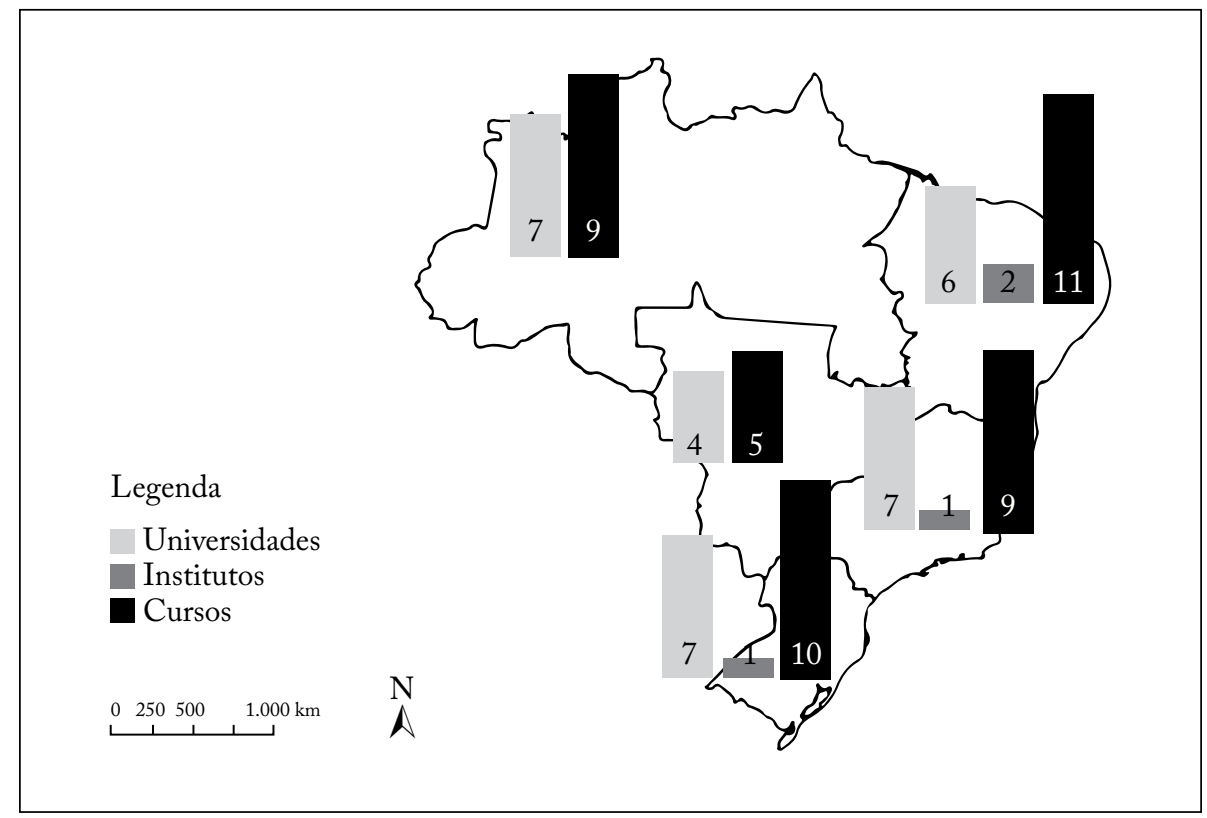

Figura 6 - Territorialização dos cursos de licenciatura em Educação do Campo, Brasil.

Fonte: Leal et al. (2019, p. 47).

A articulação das várias especificidades da matriz formativa das LECs (institucionalização da oferta da educação superior em alternância; formação por área de conhecimento; formação para gestão de processos educativos escolares e comunitários; formação de docentes capazes de desencadear a transformação da forma escolar atual, entre outros) tem gerado um número significativo de pesquisas de mestrado e doutorado, que alcança a marca de 76 trabalhos entre 2009 e 2018.

Cumpre destacar que, em função de as LECs promoverem a habilitação em todas as áreas do conhecimento, paralelamente estão sendo desencadeadas significativas ampliação e diversificação das áreas dos programas de pós-graduação nos quais se produzem trabalhos, indo além da fase inicial das pesquisas na temática, quando elas se concentravam nos programas de educação.

Atualmente, verifica-se a existência de pesquisas sobre as LECs em 17 programas de diferentes áreas do conhecimento. Foram encontradas pesquisas nos 
seguintes programas de pós-graduação: Educação; Educação, Conhecimento e Inclusão Social; Serviço Social; Processos de Desenvolvimento Humano e Saúde; Desenvolvimento Humano; Formação e Práticas Sociais; Educação Ambiental; Educação: Matemática; Agroecologia; Ciências da Comunicação em Novos Ambientes Tecnológicos; Educação Científica e Tecnológica; Linguística; Desenvolvimento, Sociedade e Cooperação Internacional; Ciências Básicas da Saúde; Ensino na Educação Básica; e ainda nos Mestrados Profissionais em Educação e Docência e em Ensino de Ciências, conforme disposto no Quadro 1.

Quadro 1 - Levantamento de produção no Banco de Teses e Dissertações da Coordenação de Aperfeiçoamento de Pessoal de Nível Superior (Capes): Licenciatura em Educação do Campo

\begin{tabular}{|c|c|c|c|c|c|}
\hline Título & Autor & Local & Nível & Ano & Programa \\
\hline $\begin{array}{c}\text { EdoC e politicas públicas no Brasil: } \\
\text { a instituição de políticas públicas } \\
\text { pelo protagonismo dos movimentos } \\
\text { sociais do campo na luta pelo direito } \\
\text { à educação }\end{array}$ & $\begin{array}{l}\text { Clarice } \\
\text { Santos }\end{array}$ & UnB & M & 2009 & Educação \\
\hline $\begin{array}{c}\text { O curso de LEdoC: Pedagogia da } \\
\text { Terra e a especificidade da formação } \\
\text { dos educadores e educadoras do campo } \\
\text { de Minas Gerais }\end{array}$ & $\begin{array}{l}\text { Sônia } \\
\text { Roseno }\end{array}$ & UFMG & M & 2010 & Educação \\
\hline $\begin{array}{c}\text { Apropriação da escrita no contexto } \\
\text { da formação de professores de ciências } \\
\text { na EdoC }\end{array}$ & Jucelia Pio & UFMG & M & 2011 & Educação \\
\hline $\begin{array}{l}\text { O potencial da LEdoC da UnB para a } \\
\text { produção de açôes contra-hegemônicas: } \\
\text { um estudo de caso no assentamento } \\
\text { Itaúna em Planaltina de GO }\end{array}$ & $\begin{array}{l}\text { Domingos } \\
\text { Trindade }\end{array}$ & UnB & M & 2011 & Educação \\
\hline $\begin{array}{l}\text { Realidade da EdoC e os desafios } \\
\text { para a formação de professores da } \\
\text { educação básica na perspectiva dos } \\
\text { movimentos sociais }\end{array}$ & $\begin{array}{c}\text { Marize } \\
\text { Carvalho }\end{array}$ & UFBA & $\mathrm{D}$ & 2011 & Educação \\
\hline $\begin{array}{l}\text { Relativismo e escolanovismo na } \\
\text { formação do educador: uma análise } \\
\text { histórico-crítica da LEdoC }\end{array}$ & $\begin{array}{l}\text { Cláudio } \\
\text { Santos }\end{array}$ & UFBA & $\mathrm{D}$ & 2011 & Educação \\
\hline $\begin{array}{c}\text { Parâmetros teórico-metodológicos } \\
\text { da formação de professores: as lições } \\
\text { derivadas da experiência da LEdoC } \\
\text { na UFBA }\end{array}$ & $\begin{array}{l}\text { Myna } \\
\text { Silveira }\end{array}$ & UFBA & M & 2012 & Educação \\
\hline $\begin{array}{l}\text { Escrita acadêmica em contexto de } \\
\text { formação de professores do campo }\end{array}$ & $\begin{array}{l}\text { Ana Paula } \\
\text { Rodrigues }\end{array}$ & UFMG & M & 2012 & Educação \\
\hline
\end{tabular}

Continua... 
Quadro 1 - Continuação

\begin{tabular}{|c|c|c|c|c|c|}
\hline Título & Autor & Local & Nível & Ano & Programa \\
\hline $\begin{array}{l}\text { Memória na prática discente: um } \\
\text { estudo em sala de aula do curso } \\
\text { LEdoC da UFMG }\end{array}$ & $\begin{array}{l}\text { Michelle } \\
\text { Correa }\end{array}$ & UFMG & M & 2012 & $\begin{array}{l}\text { Educação, } \\
\text { Conhecimento } \\
\text { e Inclusão } \\
\text { Social }\end{array}$ \\
\hline $\begin{array}{c}\text { A concepção de alternância na } L E d o C \\
\text { na UnB }\end{array}$ & $\begin{array}{l}\text { Silvanete } \\
\text { Santos }\end{array}$ & UnB & M & 2012 & Educação \\
\hline $\begin{array}{c}\text { A organização do trabalho pedagógico } \\
\text { na LEdoC/UnB: do projeto às } \\
\text { emergências e tramas do caminhar }\end{array}$ & $\begin{array}{l}\text { Anna } \\
\text { Barbosa }\end{array}$ & UnB & $\mathrm{D}$ & 2012 & Educação \\
\hline $\begin{array}{l}\text { Novos olhares, novos significados: a } \\
\text { formaçẫo de educadores do campo }\end{array}$ & $\begin{array}{c}\text { Maria } \\
\text { Osanette } \\
\text { Medeiros }\end{array}$ & UnB & $\mathrm{D}$ & 2012 & Educação \\
\hline $\begin{array}{l}\text { A formação de valores cooperativos } \\
\text { e as transformaçôes nas práticas } \\
\text { educativas: um estudo de caso de } \\
\text { educandos da LEdoC da UnB, no } \\
\text { assentamento Itaúna/GO }\end{array}$ & $\begin{array}{l}\text { Vicente } \\
\text { Silva }\end{array}$ & UnB & $\mathrm{D}$ & 2012 & Educação \\
\hline $\begin{array}{l}\text { EdoC uma politica em construção: } \\
\text { desafios para Sergipe e para o Brasil }\end{array}$ & $\begin{array}{l}\text { Marilene } \\
\text { Santos }\end{array}$ & UFS & M & 2013 & Educação \\
\hline $\begin{array}{c}\text { A apropriação do discurso cientifico } \\
\text { sobre evolução biológica por futuros } \\
\text { professores de ciências em formaçâao no } \\
\text { curso de LEdoC da UFMG }\end{array}$ & Tânia Pinto & UFMG & M & 2013 & Educação \\
\hline $\begin{array}{c}\text { Representaçôes sociais sobre a EdoC } \\
\text { construidas por educandos do curso de } \\
L E d o C\end{array}$ & $\begin{array}{l}\text { Luciane } \\
\text { Diniz }\end{array}$ & UFMG & M & 2013 & Educação \\
\hline $\begin{array}{c}\text { Representações sociais de educandas e } \\
\text { educandos do curso de LEdoC sobre a } \\
\text { leitura de textos acadêmicos }\end{array}$ & $\begin{array}{l}\text { Lucimar } \\
\text { Aquino }\end{array}$ & UFMG & M & 2013 & Educação \\
\hline $\begin{array}{l}\text { As perguntas do professor de Física e } \\
\text { a dialética da produção de sentidos na } \\
\text { formação de educadores do campo }\end{array}$ & $\begin{array}{l}\text { Marcos } \\
\text { Calazans }\end{array}$ & UFMG & M & 2013 & $\begin{array}{l}\text { Educação, } \\
\text { Conhecimento } \\
\text { e Inclusão } \\
\text { Social }\end{array}$ \\
\hline $\begin{array}{c}\text { A prática educativa e as contribuiçôes } \\
\text { do processo formativo da organicidade } \\
\text { da LEdoC da UnB: um estudo de caso } \\
\text { no território Kalunga/GO }\end{array}$ & $\begin{array}{l}\text { Elisângela } \\
\text { Pereira }\end{array}$ & UnB & M & 2013 & Educação \\
\hline $\begin{array}{c}\text { A formação política do educador do } \\
\text { campo: estudo do curso de LEdoC da } \\
\text { UnB }\end{array}$ & Júlio Silva & UnB & M & 2013 & Educação \\
\hline
\end{tabular}

Continua... 


\section{Quadro 1 - Continuação}

\begin{tabular}{|c|c|c|c|c|c|}
\hline Título & Autor & Local & Nível & Ano & Programa \\
\hline $\begin{array}{c}\text { Concepções e práticas dos sujeitos } \\
\text { envolvidos no curso de LEdoC no polo } \\
\text { de Castanbal/PA }\end{array}$ & $\begin{array}{l}\text { Maria } \\
\text { Silva }\end{array}$ & UFPA & M & 2013 & Serviço Social \\
\hline $\begin{array}{l}\text { O acesso à educação superior pelas } \\
\text { populaçôes do campo, na universidade } \\
\text { pública: um estudo do Pronera, } \\
\text { Procampo e Parfor, na UFPA }\end{array}$ & $\begin{array}{c}\text { Márcia } \\
\text { Brito }\end{array}$ & UFPA & M & 2013 & Educação \\
\hline $\begin{array}{l}\text { O que é ser educador do campo: os } \\
\text { sentidos construidos pelos estudantes } \\
\text { do Curso de LEdoC da FaE/UFMG }\end{array}$ & $\begin{array}{l}\text { Aline } \\
\text { Ângelo }\end{array}$ & UFSJ & M & 2013 & Educação \\
\hline $\begin{array}{l}\text { A pesquisa didática na experiência } \\
L E d o C \text { da UFBA: contribuição à } \\
\text { formação científica de professores }\end{array}$ & $\begin{array}{l}\text { Cláudio } \\
\text { Santos } \\
\text { Júnior }\end{array}$ & UFBA & M & 2013 & Educação \\
\hline $\begin{array}{c}\text { Uma análise dos projetos políticos } \\
\text { pedagógicos dos cursos de LEdoC no } \\
\text { estado do Paraná }\end{array}$ & $\begin{array}{l}\text { Gelson } \\
\text { Costa }\end{array}$ & Unioeste & M & 2013 & Educação \\
\hline $\begin{array}{l}\text { Conceitos de ciências para EdoC a } \\
\text { partir do tema agriculturas }\end{array}$ & $\begin{array}{l}\text { Maria José } \\
\text { Silva }\end{array}$ & $\mathrm{UnB}$ & M & 2014 & $\begin{array}{l}\text { Ensino de } \\
\text { Ciências } \\
\text { (Mestrado } \\
\text { Profissional) }\end{array}$ \\
\hline $\begin{array}{l}\text { Video como ferramenta no processo } \\
\text { formativo de licenciandos em } E d o C\end{array}$ & $\begin{array}{l}\text { Eloísa } \\
\text { Melo }\end{array}$ & $\mathrm{UnB}$ & M & 2014 & $\begin{array}{l}\text { Ensino de } \\
\text { Ciências } \\
\text { (Mestrado } \\
\text { Profissional) }\end{array}$ \\
\hline $\begin{array}{l}\text { Formação de educadores e a construção } \\
\text { da escola do campo: um estudo sobre a } \\
\text { prática educativa no Colégio Estadual } \\
\text { Vale da Esperança - Formosa/GO }\end{array}$ & $\begin{array}{l}\text { Catarina } \\
\text { Machado }\end{array}$ & $\mathrm{UnB}$ & M & 2014 & Educação \\
\hline $\begin{array}{c}\text { Educação inclusiva na formação } \\
\text { de educadores: uma experiência na } \\
\text { LEdoC da UnB }\end{array}$ & $\begin{array}{l}\text { Juliana } \\
\text { Lopes }\end{array}$ & $\mathrm{UnB}$ & M & 2014 & $\begin{array}{c}\text { Processos de } \\
\text { Desenvolvimento } \\
\text { Humano e Saúde }\end{array}$ \\
\hline $\begin{array}{l}\text { Práticas de letramentos: cartilhas } \\
\text { das minibibliotecas na formação de } \\
\text { educadores kalungas, na LEdoC UnB }\end{array}$ & $\begin{array}{l}\text { Juliana } \\
\text { Batista }\end{array}$ & $\mathrm{UnB}$ & M & 2014 & Educação \\
\hline $\begin{array}{l}\text { As contribuições da LEdoC na } \\
\text { transformação das relaçôes de gênero: } \\
\text { um estudo de caso com as educandas do } \\
\text { assentamento Virgilândia de Formosa/GO }\end{array}$ & $\begin{array}{l}\text { Maria de } \\
\text { Lourdes } \\
\text { Pereira }\end{array}$ & UnB & M & 2014 & Educação \\
\hline $\begin{array}{l}\text { Comunicação e tecnologias da } \\
\text { informaçẫo na formação de educadores } \\
\text { para ampliação das perspectivas } \\
\text { críticas dos sujeitos na LEdoC da UnB }\end{array}$ & $\begin{array}{l}\text { Márcio } \\
\text { Ferreira }\end{array}$ & $\mathrm{UnB}$ & $\mathrm{D}$ & 2014 & Educação \\
\hline
\end{tabular}

Continua... 
Quadro 1 - Continuação

\begin{tabular}{|c|c|c|c|c|c|}
\hline Título & Autor & Local & Nível & Ano & Programa \\
\hline $\begin{array}{l}\text { Representaçôes sociais da EdoC: } \\
\text { formação e identidade docente }\end{array}$ & $\begin{array}{l}\text { Alessandra } \\
\text { Dias }\end{array}$ & UNITAU & M & 2014 & $\begin{array}{l}\text { Desenvolvimento } \\
\quad \text { Humano: } \\
\text { Formação, Políticas } \\
\text { e Práticas Sociais }\end{array}$ \\
\hline $\begin{array}{c}\text { A educação ambiental no curso } \\
\text { LEdoC: uma análise à luz da } \\
\text { educação ambiental ecomunitarista e } \\
\text { do ecomunitarismo (o caso da Turma } \\
1 \text { - UAB/UFPel Pelotas RS) }\end{array}$ & $\begin{array}{l}\text { Raquel } \\
\text { Ávila }\end{array}$ & Furg & M & 2014 & $\begin{array}{l}\text { Educação } \\
\text { Ambiental }\end{array}$ \\
\hline $\begin{array}{l}\text { Os desafios da LEdoC no IFPA - } \\
\text { campus de Abaetetuba/PA }\end{array}$ & $\begin{array}{l}\text { Elane } \\
\text { Bentes }\end{array}$ & UFPA & M & 2014 & Serviço Social \\
\hline $\begin{array}{l}\text { Formação superior em agroecologia } \\
\text { e EdoC: práticas sociais que } \\
\text { transbordam áreas de conbecimento }\end{array}$ & $\begin{array}{l}\text { Thiago } \\
\text { Gomes }\end{array}$ & UFV & M & 2014 & Agroecologia \\
\hline $\begin{array}{l}\text { As TICs na EdoC: uma análise da } \\
\text { situação do estado do Rio de Janeiro }\end{array}$ & $\begin{array}{c}\text { Katja } \\
\text { Augusto }\end{array}$ & Unesp & $\mathrm{D}$ & 2014 & $\begin{array}{c}\text { Ciências da } \\
\text { Comunicação: } \\
\text { Comunicação } \\
\text { em Novos } \\
\text { Ambientes } \\
\text { Tecnológicos }\end{array}$ \\
\hline $\begin{array}{c}\text { Entendimentos a respeito da } \\
\text { matemática na EdoC: questôes sobre } \\
\text { currículo }\end{array}$ & $\begin{array}{l}\text { Linlya } \\
\text { Barbosa }\end{array}$ & Unesp & $\mathrm{D}$ & 2014 & $\begin{array}{l}\text { Educação } \\
\text { Matemática: } \\
\text { Instituto de } \\
\text { Geociências } \\
\text { e Ciências } \\
\text { Exatas }\end{array}$ \\
\hline $\begin{array}{l}\text { Práticas artísticas dos estudantes } \\
\text { do curso de LEdoC: um estudo na } \\
\text { perspectiva das representações sociais }\end{array}$ & $\begin{array}{l}\text { Cristiene } \\
\text { Carvalho }\end{array}$ & UFMG & M & 2015 & $\begin{array}{l}\text { Educação, } \\
\text { Conhecimento e } \\
\text { Inclusão Social }\end{array}$ \\
\hline LEdoC: um processo em construção & $\begin{array}{l}\text { Érika } \\
\text { Sagae }\end{array}$ & UFSC & M & 2015 & Educação \\
\hline $\begin{array}{c}\text { LEdoC: relações entre UFRRJ e os } \\
\text { movimentos sociais }\end{array}$ & $\begin{array}{l}\text { Larissa } \\
\text { Cabral }\end{array}$ & UFRRJ & M & 2015 & Educação \\
\hline $\begin{array}{c}\text { O tutor no curso de LEdoC UAB/ } \\
\text { UFPel }\end{array}$ & $\begin{array}{l}\text { Liana } \\
\text { Porto }\end{array}$ & UFPel & M & 2015 & Educação \\
\hline $\begin{array}{l}\text { Os conteúdos de ensino referentes } \\
\text { aos saberes campesinos presentes no } \\
\text { currículo da formação de professores } \\
\text { de um curso de LEdoC do sertão } \\
\text { pernambucano: uma leitura através dos } \\
\text { estudos pós-coloniais latino-americanos }\end{array}$ & $\begin{array}{l}\text { Jéssica } \\
\text { Silva }\end{array}$ & UFPE & M & 2015 & Educação \\
\hline
\end{tabular}




\section{Quadro 1 - Continuação}

\begin{tabular}{|c|c|c|c|c|c|}
\hline Título & Autor & Local & Nível & Ano & Programa \\
\hline $\begin{array}{l}\text { Formação inicial e identidade docente } \\
\text { de licenciandos em EdoC: um estudo } \\
\text { no Vale do Paraiba }\end{array}$ & $\begin{array}{l}\text { Walquíria } \\
\text { Audi }\end{array}$ & UNITAU & M & 2015 & $\begin{array}{l}\text { Desenvolvimento } \\
\text { Humano }\end{array}$ \\
\hline $\begin{array}{l}\text { Conceppcão e prática da organização } \\
\text { escolar desenvolvido no curso de } \\
\text { LEdoC da UFS (2008/2012) }\end{array}$ & $\begin{array}{l}\text { Leandro } \\
\text { Santos }\end{array}$ & UFS & M & 2015 & Educação \\
\hline $\begin{array}{c}\text { Docência, escola do campo e formação: } \\
\text { qual o lugar do trabalho coletivo? }\end{array}$ & $\begin{array}{l}\text { Maria } \\
\text { Ferreira }\end{array}$ & $\mathrm{UnB}$ & $\mathrm{D}$ & 2015 & Educação \\
\hline $\begin{array}{c}\text { Formação de educadores do campo e } \\
\text { tecnologias digitais: relaçóes e desafios } \\
\text { na LEdoC da UnB }\end{array}$ & $\begin{array}{l}\text { Wanessa } \\
\text { Castro }\end{array}$ & $\mathrm{UnB}$ & $\mathrm{D}$ & 2015 & Educação \\
\hline $\begin{array}{l}\text { Por uma pedagogia com foco no } \\
\text { sujeito: um estudo na } L E d o C\end{array}$ & $\begin{array}{l}\text { Ana } \\
\text { Orofino }\end{array}$ & $\mathrm{UnB}$ & $\mathrm{D}$ & 2015 & Educação \\
\hline $\begin{array}{l}\text { Sociolinguística e seu lugar nos letramentos } \\
\text { acadêmicos de professores do campo }\end{array}$ & $\begin{array}{l}\text { Ana } \\
\text { Moura }\end{array}$ & $\mathrm{UnB}$ & $\mathrm{D}$ & 2015 & Linguística \\
\hline $\begin{array}{l}\text { Questão agrária, EdoC e formação de } \\
\text { professores: territórios em disputa }\end{array}$ & $\begin{array}{l}\text { Janeide } \\
\text { Santos }\end{array}$ & UFBA & $\mathrm{D}$ & 2015 & Educação \\
\hline $\begin{array}{l}\text { Da semente à flor: emergências } \\
\text { emancipatórias na LEdoC da UFV }\end{array}$ & $\begin{array}{l}\text { Manuelli } \\
\text { Kölin }\end{array}$ & UFV & M & 2016 & Educação \\
\hline $\begin{array}{l}\text { Trajetórias escolares dos licenciandos } \\
\text { em EdoC da UFV }\end{array}$ & $\begin{array}{l}\text { Natália } \\
\text { Lopes }\end{array}$ & UFV & M & 2016 & Educação \\
\hline $\begin{array}{c}\text { LEdoC: propostas em disputa na } \\
\text { perspectiva de estudantes do curso de } \\
\text { Matemática da UFMG }\end{array}$ & $\begin{array}{l}\text { Josinalva } \\
\text { Sá }\end{array}$ & UFMG & M & 2016 & $\begin{array}{l}\text { Educação, } \\
\text { Conhecimento } \\
\text { e Inclusão social }\end{array}$ \\
\hline $\begin{array}{l}\text { Letramento digital e a prática de } \\
\text { alunos do Lecampo em sala de aula: } \\
\text { estudo sobre possíveis repercussóes do } \\
\text { ensino de informática básica na EdoC }\end{array}$ & $\begin{array}{l}\text { Anderson } \\
\text { Santos }\end{array}$ & UFMG & M & 2016 & $\begin{array}{c}\text { Mestrado } \\
\text { Profissional } \\
\text { em Educação e } \\
\text { Docência }\end{array}$ \\
\hline $\begin{array}{l}\text { Representaçôes sociais de educandos do } \\
\text { curso de LEdoC sobre a violência }\end{array}$ & $\begin{array}{l}\text { Luiz } \\
\text { Ribeiro }\end{array}$ & UFMG & $\mathrm{D}$ & 2016 & $\begin{array}{l}\text { Educação, } \\
\text { Conhecimento } \\
\text { e Inclusão } \\
\text { social }\end{array}$ \\
\hline $\begin{array}{l}\text { Discursos que revelam o letramento } \\
\text { acadêmico na (re) constituição } \\
\text { identitária dos educandos da LEdoC }\end{array}$ & $\begin{array}{l}\text { Ana } \\
\text { Araújo }\end{array}$ & $\mathrm{UnB}$ & M & 2016 & Linguística \\
\hline $\begin{array}{l}\text { Matrizes formativas e organização } \\
\text { pedagógica: contradiçôes na transição } \\
\text { da escola rural para escola do campo }\end{array}$ & $\begin{array}{l}\text { Pedro } \\
\text { Xavier }\end{array}$ & $\mathrm{UnB}$ & M & 2016 & Educação \\
\hline
\end{tabular}




\section{Quadro 1 - Continuação}

\begin{tabular}{|c|c|c|c|c|c|}
\hline Título & Autor & Local & Nível & Ano & Programa \\
\hline $\begin{array}{l}\text { Memórias de estudantes kalunga } \\
\text { que ingressaram no ensino superior: } \\
\text { LEdoC/UnB }\end{array}$ & $\begin{array}{l}\text { Raquel } \\
\text { Koyanagi }\end{array}$ & UnB & $\mathrm{D}$ & 2016 & $\begin{array}{l}\text { Desenvolvimento, } \\
\text { Sociedade e } \\
\text { Cooperação } \\
\text { Internacional }\end{array}$ \\
\hline $\begin{array}{l}\text { Representaçôes sociais de egressos do } \\
\text { curso de LEdoC da UFPA: formação e } \\
\text { atuação no contexto social do campo }\end{array}$ & $\begin{array}{l}\text { Atenor } \\
\text { Trindade }\end{array}$ & UFPA & M & 2016 & Educação \\
\hline $\begin{array}{l}\text { A formação de professores para } \\
\text { a educação do campo: estudo } \\
\text { epistemológico sobre a produção de } \\
\text { conhecimento na área }\end{array}$ & $\begin{array}{l}\text { Charlene } \\
\text { Santos }\end{array}$ & Uesb & M & 2016 & Educação \\
\hline $\begin{array}{c}\text { Tudo é rede, conexão e simultaneidade! } \\
\text { Problematizaçôes foucaultianas sobre } \\
\text { a interdisciplinaridade: um campo } \\
\text { interdisciplinar de enunciabilidades } \\
\text { disciplinares }\end{array}$ & $\begin{array}{l}\text { Verônica } \\
\text { Mittmann }\end{array}$ & UFRGS & M & 2017 & $\begin{array}{l}\text { Ciências } \\
\text { Básicas da } \\
\text { Saúde }\end{array}$ \\
\hline $\begin{array}{l}\text { Reflexões sobre a formação docente } \\
\text { na área de conhecimento ciências da } \\
\text { natureza: a LEdoC-UFSC }\end{array}$ & $\begin{array}{l}\text { Leila } \\
\text { Paiter }\end{array}$ & UFSC & M & 2017 & $\begin{array}{l}\text { Educação } \\
\text { Científica e } \\
\text { Tecnológica }\end{array}$ \\
\hline $\begin{array}{c}\text { Trabalho coletivo, } \\
\text { interdisciplinaridade e auto- } \\
\text { organização dos educandos: } \\
\text { contribuiçôes da LEdoC para práticas } \\
\text { educativas contra hegemônicas na } \\
\text { experiência do ProJovem Campo } \\
\text { Saberes da Terra do DF }\end{array}$ & $\begin{array}{l}\text { Elizana } \\
\text { Santos }\end{array}$ & $\mathrm{UnB}$ & M & 2017 & Educação \\
\hline $\begin{array}{l}\text { Formação de professores na perspectiva } \\
\text { da epistemologia da práxis: análise } \\
\text { da atuação dos egressos do curso de } \\
\text { LEdoC UnB }\end{array}$ & $\begin{array}{l}\text { Márcia } \\
\text { Brito }\end{array}$ & UnB & $\mathrm{D}$ & 2017 & Educação \\
\hline $\begin{array}{c}\text { LEdoC e movimentos sociais: análise } \\
\text { do curso da UFMG }\end{array}$ & $\begin{array}{l}\text { Amarildo } \\
\text { Horácio }\end{array}$ & UFV & M & 2017 & Educação \\
\hline $\begin{array}{c}\text { LEdoC do IF de Educação, Ciência e } \\
\text { Tecnologia do Pará: estudos sobre sua } \\
\text { organização curricular }\end{array}$ & $\begin{array}{l}\text { Adalcilena } \\
\text { Duarte }\end{array}$ & $\begin{array}{l}\text { PUC- } \\
\text { SP }\end{array}$ & M & 2017 & Educação \\
\hline $\begin{array}{c}\text { Caminhos da interdisciplinaridade: } \\
\text { da formação por área de conhecimento } \\
\text { à prática educativa de egressos da } \\
\text { LEdoC-Procampo/IFPA, Campus } \\
\text { de Castanhal, } P A\end{array}$ & $\begin{array}{l}\text { Márcia } \\
\text { Silva }\end{array}$ & UFC & $\mathrm{D}$ & 2017 & $\begin{array}{l}\text { Educação } \\
\text { Brasileira }\end{array}$ \\
\hline
\end{tabular}




\section{Quadro 1 - Continuação}

\begin{tabular}{|c|c|c|c|c|c|}
\hline Título & Autor & Local & Nível & Ano & Programa \\
\hline $\begin{array}{c}\text { Representaçôes sociais das práticas } \\
\text { artísticas na atuação de professores do } \\
\text { Campo }\end{array}$ & $\begin{array}{l}\text { Cristiene } \\
\text { Carvalho }\end{array}$ & UFMG & $\mathrm{D}$ & 2017 & Educação \\
\hline $\begin{array}{l}\text { Política de formação de educadores } \\
\text { do campo e a construção da contra- } \\
\text { hegemonia via epistemologia da } \\
\text { práxis: análise da experiência da } \\
\text { LEdoC-UFPA-Cametá }\end{array}$ & $\begin{array}{l}\text { Hellen } \\
\text { Silva }\end{array}$ & UFPA & $\mathrm{D}$ & 2017 & Educação \\
\hline $\begin{array}{l}\text { LEdoC: ressignificando a relação } \\
\text { entre a pós-graduação e a graduação } \\
\text { na práxis da docência }\end{array}$ & $\begin{array}{l}\text { Sérgio } \\
\text { Teixeira }\end{array}$ & UnB & M & 2018 & Educação \\
\hline $\begin{array}{c}\text { Sociolinguística: da oralidade à escrita } \\
\text { na formação de docentes do campo da } \\
\text { área de linguagem }\end{array}$ & $\begin{array}{l}\text { Ana } \\
\text { Carolina } \\
\text { Melo }\end{array}$ & $\mathrm{UnB}$ & M & 2018 & Linguística \\
\hline $\begin{array}{l}\text { A LEdoC no estado de Roraima: } \\
\text { contribuiçốs para a escola do campo }\end{array}$ & $\begin{array}{l}\text { Silvanete } \\
\text { Santos }\end{array}$ & UnB & $\mathrm{D}$ & 2018 & Educação \\
\hline $\begin{array}{l}\text { O uso de sequências didáticas na } \\
\text { formação inicial de professores da } \\
\text { EdoC em questöes ambientais na } \\
\text { perspectiva da totalidade }\end{array}$ & $\begin{array}{l}\text { Alessandra } \\
\text { Stauffer }\end{array}$ & Ufes & M & 2018 & $\begin{array}{l}\text { Ensino na } \\
\text { Educação } \\
\text { Básica }\end{array}$ \\
\hline $\begin{array}{l}\text { A produção da LEdoC no Brasil: as } \\
\text { múltiplas determinaçôes na disputa } \\
\text { por projetos societários }\end{array}$ & $\begin{array}{l}\text { Valdirene } \\
\text { Moraes }\end{array}$ & UTP & $\mathrm{D}$ & 2018 & Educação \\
\hline $\begin{array}{c}\text { Formação de professores: realidade, } \\
\text { contradições e possibilidade do curso de } \\
\text { LEdoC/UFFS - Campus Laranjeiras } \\
\text { do Sul (2012-2017) }\end{array}$ & $\begin{array}{l}\text { Edson } \\
\text { Anhaia }\end{array}$ & UFSC & $\mathrm{D}$ & 2018 & Educação \\
\hline $\begin{array}{c}\text { Política de formação de professores: } \\
\text { análise da institucionalização do } \\
\text { curso de EdoC da UFT-Campus } \\
\text { de Arraias }\end{array}$ & Suze Sales & UFSCar & $\mathrm{D}$ & 2018 & Educação \\
\hline
\end{tabular}

EdoC: Educação do Campo; UnB: Universidade de Brasília; M: Mestrado; LEdoC: Licenciatura em Educação do Campo; UFMG: Universidade Federal de Minas Gerais; UFBA: Universidade Federal da Bahia; D: Doutorado; UFS: Universidade Federal de Sergipe; UFPA: Universidade Federal do Pará; Pronera: Programa Nacional de Educação na Reforma Agrária; Procampo: Programa de Apoio à Formação Superior em Licenciatura em Educação do Campo; Parfor: Programa Nacional de Formação de Professores da Educação Básica; FaE: Faculdade de Educação; UFSJ: Universidade Federal de São João del-Rei; Unioeste: Universidade Estadual do Oeste do Paraná; UAB: Universidade Aberta do Brasil; UFPel: Universidade Federal de Pelotas; Furg: Universidade Federal do Rio Grande; IFPA: Instituto Federal de Educação, Ciência e Tecnologia do Pará; UFV: Universidade Federal de Viçosa; TICs: tecnologias da informação e da comunicação; Unesp: Universidade Estadual Paulista "Júlio de Mesquita Filho"; UFSC: Universidade Federal de Santa Catarina; UFRRJ: Universidade Federal Rural do Rio de Janeiro; UFPE: Universidade Federal de Pernambuco; Lecampo: Licenciatura em Educação do Campo; Uesb: Universidade Estadual do Sudoeste da Bahia; UFRGS: Universidade Federal do Rio Grande do Sul; PUC-SP: Pontifícia Universidade Católica de São Paulo; IF: Instituto Federal; UFC: Universidade Federal do Ceará; Ufes: Universidade Federal do Espírito Santo; UFFS: Universidade Federal da Fronteira Sul; UFT: Universidade Federal do Tocantins; UFSCar: Universidade Federal de São Carlos.

Fonte: Molina (2019). 
O maior grupo de teses e dissertações identificadas, que somam 19 pesquisas, abordam questões referentes aos desafios enfrentados nos cursos relativos aos processos de apropriação dos conhecimentos científicos pelos camponeses nas LECs. Há trabalhos que apresentam questões inovadoras sobre os desafios e as potencialidades dos processos de aprendizagem dos educadores camponeses que se desenvolvem nos cursos, tanto em disciplinas integrantes das ciências da natureza quanto em estudos específicos na construção das aprendizagens na área das linguagens com ênfase nos estudos da sociolinguística.

Há trabalhos relevantes nessa área que abordam questões teórico-práticas enfrentadas nos cursos acerca dos desafios do processo de aprendizagem dos educadores do campo quanto ao acesso à língua culta e à sua apropriação. São desafios que dizem respeito, ao mesmo tempo, à garantia do direito dos sujeitos camponeses à linguagem acadêmica e científica e à obrigação da universidade em garantir-lhes esses ensinamentos, mas sem promover, com esse acesso, a perda da identidade cultural nem das especificidades das formas locais de falar dos coletivos camponeses presentes nos cursos, como dos quilombolas e ribeirinhos, por exemplo (Moura, 2015; Araújo, 2016; Melo, 2018).

Encontrou-se também um grupo significativo de trabalhos que tratam das formas de pensar, sentir e agir dos estudantes das LECs com base na abordagem das representações sociais em movimento (Antunes-Rocha e Ribeiro, 2018). São teses e dissertações que discutem como os conhecimentos do cotidiano e conhecimentos científicos são construídos nos processos de formação e prática docente dos egressos. Temas como violência no campo, leitura, escrita, práticas artísticas e outros são abordados como questões geradas em um tempo/espaço historicamente produzido e marcado por interesses de grupos sociais (Aquino, 2013; Ribeiro, 2016; Benfica, 2017; Carvalho, 2018; Gomes, 2018). Com base nesses estudos, é possível perceber como os processos formativos dos cursos enfatizam a construção de saberes numa perspectiva problematizadora, dialética e comprometida com a luta para garantir as formas de produzir e reproduzir a vida no contexto camponês.

Em pesquisas sobre práticas de ensino no âmbito das ciências da natureza desenvolvidas nas LECs com foco no ensino de física, de matemática e de biologia (Pinto, 2013; Calazans, 2013; Barbosa, 2014), tem surgido o questionamento no tocante a como produzir processos de ensino-aprendizagem que de fato sejam capazes de incorporar os conhecimentos dos sujeitos camponeses nos processos. O fato de eles próprios se titularem como docentes para as escolas do campo tem provocado uma variada gama de novas situações aos docentes da universidade dessa área de conhecimento que trabalham nessas licenciaturas.

Faz-se importante destacar que não se entende como contradição os estudos disciplinares, em função de as LECs objetivarem a promoção da formação por áreas de habilitação. Como já afirmado em textos anteriores (Caldart, 2011; Molina, 2017), a formação por áreas não prescinde, de forma nenhuma, do aprofundamento dos estudos disciplinares. É significativo ressaltar também que foram encontrados trabalhos que trazem reflexões bastante avançadas sobre a experiência e o sentido da formação por áreas de conhecimento na LEC. Entre eles, estão os trabalhos de 
Paiter (2017) e Silva (2017), com relevantes contribuições para a sistematização das experiências da proposta formativa realizada nas LECs.

No contexto das escolas do campo, a formação por áreas do conhecimento representa uma alternativa que possibilita mais intensamente o exercício da práxis e a aproximação da educação do campo com a realidade camponesa. Em sua pesquisa, Paiter (2017) retoma o potencial desse modo de organização curricular na tentativa de desfragmentação do currículo, visando à superação da tradição compartimentada e isolada das questões da vida que estão postas tradicionalmente na maneira como a escola trata o processo de escolarização dos sujeitos. A forma como o conhecimento vem sendo historicamente produzido e transposto para os processos escolares, segundo uma lógica capitalista de organização do ensino, desvela hiatos entre o fazer pedagógico e as relações sociais, políticas, econômicas e ambientais externas à escola; rupturas entre o discurso teórico e a prática social; distanciamento entre a organização curricular e a compreensão da materialidade da vida; negligência com os problemas que emergem da realidade dos sujeitos; distanciamento entre os conteúdos e a prática social, em razão da fragmentação, da compartimentalização e do isolamento das disciplinas (Paiter, 2017). A formação por área tem potencial significativo para a superação desses entraves, conforme os resultados encontrados na pesquisa de Paiter (2017).

Ainda no âmbito da importância das investigações sobre a interdisciplinaridade e áreas nas LECs, é relevante destacar algumas pesquisas que avançaram nas reflexões a respeito de como as práticas nas LECs articulam o debate entre as diferentes áreas do conhecimento, possibilitando espaços de germinação de ricas transformações na produção e circulação do conhecimento científico. Nesse sentido, encontram-se os trabalhos que desenvolveram pesquisas registrando as articulações de experiências didáticas presentes nos cursos que vincularam temas das ciências da natureza a temas das áreas de linguagens, construindo práticas inovadoras na formação docente. Entre eles, aponta-se o de Pio (2011), desenvolvido no Programa de Pós-Graduação em Educação da UFMG, no qual a autora reflete quanto a uma experiência da LEC com a turma de habilitação em Ciências de 2008, em que se construiu um diálogo entre a educação do campo, a educação em ciências e a mediação da leitura e da escrita nos espaços formativos, relacionado com um projeto de ensino concebido pela área de ciências da vida e da natureza que privilegiou a formação de professores leitores e produtores de textos didáticos de ciências.

Nessa direção, também é significativo o registro da experiência analisada na dissertação de Batista (2014), na qual se articulam linguagens e ciências da natureza com base no uso do Acervo das Minibibliotecas da Empresa Brasileira de Pesquisa Agropecuária (Embrapa), nas escolas do campo da Região Centro-Oeste. Mediante oficinas que envolvem o uso de materiais didáticos das minibibliotecas em associação com o exercício da análise textual do conteúdo de parte do acervo, especialmente as cartilhas sobre os frutos do cerrado, cotejando na leitura e no estudo coletivo dos textos os saberes dos educados, as finalidades e os usos medicinais desses frutos com a experiência da reescrita dos textos, por intermédio do trabalho coletivo de docentes de biologia, ecologia e linguagens (Batista, 2014), obteve-se uma rica interação entre as diferentes áreas de habilitação. Estas também têm sido 
importantes contribuições das LECs: desencadear, estimular e promover o trabalho coletivo dos educadores da universidade, buscando novas formas de realizar os processos de ensino-aprendizagem, considerando-se as especificidades dos educandos do campo que estão nas LECs. Entre os trabalhos analisados, há uma tese que traz relevantes reflexões teóricas sobre os desafios e as contribuições das LECs para a promoção do trabalho coletivo dos docentes (Ferreira, 2015), condição sine qua non para a promoção efetiva do trabalho interdisciplinar e para a formação por área de conhecimento.

As questões, as potencialidades, os desafios e mesmo os impedimentos para a realização da alternância (Santos, 2012) idealizada inicialmente, em função da ausência de recursos e condições de infraestrutura nas instituições de ensino superior, são abordados em outro grupo grande de trabalhos que reúne 10 pesquisas e que tratam do registro de todos os aspectos das LECs analisadas, na sua maioria, como estudo de caso de determinado curso. Refletindo sobre o projeto político-pedagógico de cada um desses cursos e seus desafios na implementação da experiência, passando pelas estratégias de ingresso, condições de permanência, instigações da promoção da formação por área de conhecimento e pelas estratégias de implementação da alternância, essas pesquisas possibilitam um olhar geral para os cursos, compreendendo os desafios presentes tanto no tempo universidade quanto no tempo comunidade. Para além disso, a riqueza está em garantir o registro de experiências únicas, como pesquisas, por exemplo, sobre LECs oferecidas por institutos federais aos ribeirinhos do Pará (Bentes, 2014), ou as especificidades de processos pedagógicos de turmas com a presença de indígenas ou um grande número de quilombolas. Embora os cursos e as experiências sejam bastante heterogêneos, o registro desses processos oferece uma imensa contribuição, pois permite a construção de um olhar amplo sobre como se materializam os cursos. Há pesquisas desse tipo acerca do registro do curso como um todo nas cinco regiões. Apesar de não haver nessas pesquisas maior aprofundamento teórico das categorias trabalhadas, sobressai a riqueza do registro das experiências como memória histórica da classe trabalhadora.

Um quarto grupo de pesquisas reflete quanto a questões centrais à consolidação da proposta formativa das LECs e da constituição da identidade do respectivo educador. Com base na análise de projetos político-pedagógicos dos cursos e de sua concretização, esses trabalhos explicitam as contradições entre a epistemologia da prática e a epistemologia da práxis (matriz da LEC) e apresentam os elementos que lhes permitem afirmar a LEC no âmbito da epistemologia da práxis. Tais trabalhos trazem significativas contribuições teóricas ao sistematizar os principais elementos no âmbito da teoria pedagógica que fundamentam as práticas concebidas e materializadas pelas LECs por eles analisadas (Brito, 2017; Silva, 2017).

$\mathrm{Na}$ mesma direção, destacamos o trabalho de Santos (2016), que se dispôs a fazer um estudo epistemológico sistematizando a produção do conhecimento acadêmico em teses e dissertações elaboradas entre os anos de 2010 e 2014 sobre a formação de professores para a educação do campo. Com base na análise de 15 trabalhos (seis teses e nove dissertações defendidas no mencionado intervalo), foi feita uma discussão sobre as concepções de formação de professores pela relação trabalho e educação sustentada no materialismo histórico dialético. No estudo, foram 
analisados os cursos de Pedagogia da Terra e de LEC, tendo como foco principal explicitar o quadro de concepções que vêm sendo desenvolvidas sobre a formação docente para as escolas do campo. Foi observada a hegemonia das perspectivas críticas nesses processos formativos.

De acordo com Santos (2016), conforme os dados encontrados nos trabalhos analisados, é possível concluir que a formação de professores para a educação do campo, que é uma importante bandeira de luta dos movimentos sociais e sindicais, tem consistido num marco de formação crítica capaz de indicar importantes rupturas com a matriz hegemônica de formação docente no país. $\mathrm{O}$ argumento que se busca desenvolver neste artigo, concernente à importância do protagonismo dos próprios sujeitos camponeses na mudança dos processos de produção de conhecimento, é reforçado pela autora quando conclui que a produção acadêmica desses sujeitos consiste em um importante instrumento para o fortalecimento da educação do campo, da formação de professores como um todo e, portanto, da educação de modo geral. À medida que são implementados, os cursos de formação de professores do campo (Pedagogia da Terra e LEC) contribuem não apenas para formar os educadores e educadoras do campo, mas também para repensar o modelo de formação que tem sido desenvolvido pelo modelo de estado neoliberal, sendo a organização coletiva e o protagonismo dos estudantes determinantes para a consolidação da formação de acordo com os princípios de educação e de formação defendidos pelos movimentos sociais do campo (Santos, 2016).

Com outro enfoque, mas também na perspectiva do registro das lutas das classes trabalhadoras no processo de conquista dos direitos, há um quinto conjunto de dissertações e teses com trabalhos trazendo questões sobre a constituição e a implantação da LEC como política pública, forjada por intermédio do protagonismo do movimento camponês. Tais trabalhos refletem acerca das tensões e contradições presentes nas disputas com o Estado para a implantação da proposta, bem como quanto aos desafios da manutenção dos princípios da educação do campo no próprio processo de institucionalização das experiências pesquisadas. Trazem reflexões relevantes pertinentes aos debates em torno das questões que tratam das particularidades, especificidades e universalidade do direito à educação dos camponeses (Santos, 2009; Brito, 2013; Moraes, 2018).

As questões referentes à manutenção ou não do protagonismo dos sujeitos camponeses, seja dos movimentos sociais e sindicais, seja dos estudantes no cotidiano do curso por meio da auto-organização, também consistem em importantes temas de pesquisa. Há estudos que refletem a respeito de como tem ocorrido a auto-organização dos camponeses vinculados a esses movimentos nas novas graduações, examinando teoricamente as potencialidades de tal categoria no processo de formação docente até os resultados de sua atuação nas comunidades rurais de origem resultante do reflexo dos aprendizados da auto-organização vivenciada nos cursos (Pereira, 2013). Há ainda estudos que ponderam sobre os aprendizados da auto-organização na formação docente vivenciada nas LECs e os desdobramentos desses aprendizados na atuação dos egressos em outras políticas públicas de educação do campo, como o Saberes da Terra e o Pronera (Santos, 2017). Destaca-se que existem diferentes trabalhos de mestrado que foram encontrados na pesquisa 
realizada e que são produzidos por estudantes camponeses egressos das próprias LECs, como da UnB, da UFMG e da Universidade Federal de Santa Catarina (UFSC), por exemplo.

Os programas de pós-graduação nos quais foram produzidas essas pesquisas estão distribuídos entre 21 universidades no país, sendo 15 federais, presentes nas cinco regiões (Universidade Federal do Pará — UFPA; Universidade Federal de Pernambuco - UFPE; Universidade Federal do Ceará - UFC; UFBA; UnB; Universidade Federal do Rio de Janeiro - UFRJ; Universidade Federal de Viçosa - UFV; UFMG; Universidade Federal de São Carlos - UFSCar; UFS; Universidade Federal de São João Del-Rei - UFSJ; Universidade Federal do Rio Grande - Furg; Universidade Federal do Rio Grande do Sul — UFRGS; UFSC; e Universidade Federal de Pelotas - UFPel), três estaduais (Universidade Estadual do Oeste do Paraná - Unioeste; Universidade Estadual Paulista "Júlio de Mesquita Filho" - Unesp; e Universidade Estadual do Sudoeste da Bahia - Uesb) e três particulares (Universidade de Taubaté; Pontifícia Universidade Católica de São Paulo - PUC-SP; e Universidade do Tuiuti do Paraná). O Quadro 2 indica que os trabalhos estão concentrados em universidades das regiões Centro-Oeste (27) e Sudeste (24), havendo presença majoritária das pesquisas em instituições que ofertaram as licenciaturas desde sua experiência piloto, seguindo-se as regiões Nordeste (11 trabalhos), Sul (nove) e Norte (cinco).

\section{DESAFIOS E POSSIBILIDADES NA CONSTRUÇÃO DA RESISTÊNCIA E DEFESA DOS DIREITOS}

Os dados obtidos nesta pesquisa sinalizam para um conjunto de desafios e de possibilidades. Sem pretender esgotar todos os itens que poderiam aqui ser discutidos, foram selecionados aqueles considerados como mais evidentes de ser identificados pelo conjunto das discussões apresentadas.

No contexto da crise estrutural do capital, da necessidade de construção de novos nichos de acumulação e de controle do processo educativo para garantir a elevação dos níveis de escolaridade e de produtividade atualmente exigidos para a manutenção das taxas de lucro dos capitalistas, a educação pública brasileira está sob forte ataque privatista. Conforme se observou anteriormente, não se podem separar as lutas da educação do campo das lutas gerais em defesa da educação pública. Em outras palavras, deve-se manter a especificidade das lutas pela educação do campo, porque as desigualdades sociais e educacionais ainda são imensas, porém só se terá vitória nas lutas específicas se realizadas juntamente com aquelas mais amplas e articuladas em defesa da manutenção da educação no âmbito dos direitos, área que enfrenta nesse período histórico gravíssimo processo de disputa para a sua total transformação em mercadoria, para a sua retirada do âmbito público dos direitos universais.

Um segundo desafio diz respeito à posição assumida de que a educação do campo está inserida na disputa entre modelos agrícolas na sociedade brasileira e suas implicações para o modelo de educação e de sociedade como um todo. A lógica do agronegócio e a da agricultura familiar camponesa representam duas concepções de sociedade que impactam de maneiras totalmente distintas na organização econô- 
Quadro 2 - Distribuição das teses e dissertações sobre licenciatura em Educação do Campo entre os estados e regiões brasileiras.

\begin{tabular}{|c|c|c|c|}
\hline Região & $\begin{array}{c}\text { Teses e } \\
\text { Dissertações }\end{array}$ & Estado & $\begin{array}{l}\text { Programas de } \\
\text { Pós-Graduação }\end{array}$ \\
\hline Norte & 5 & Pará (5) & $\begin{array}{c}\text { Serviço Social } \\
\text { Educação }\end{array}$ \\
\hline \multirow{4}{*}{ Nordeste } & \multirow{4}{*}{11} & Sergipe (2) & Educação \\
\hline & & Ceará (1) & Educação Brasileira \\
\hline & & Pernambuco (1) & Educação \\
\hline & & Bahia (7) & Educação \\
\hline \multirow{4}{*}{ Sudeste } & \multirow{4}{*}{24} & Minas Gerais (17) & $\begin{array}{c}\text { Educação } \\
\text { Educação, Conhecimento e Inclusão } \\
\text { Social } \\
\text { Educação e Docência } \\
\text { Agroecologia }\end{array}$ \\
\hline & & São Paulo (5) & $\begin{array}{c}\text { Educação } \\
\text { Ciências da Comunicação } \\
\text { Educação Matemática } \\
\text { Desenvolvimento Humano } \\
\text { Ensino na Educação Básica }\end{array}$ \\
\hline & & Rio de Janeiro (1) & Educação \\
\hline & & Espírito Santo (1) & Ensino na Educação Básica \\
\hline Centro-Oeste & 27 & Brasília (27) & $\begin{array}{c}\text { Educação } \\
\text { Ensino de Ciências } \\
\text { Processos de Desenvolvimento } \\
\text { Humano e Saúde } \\
\text { Linguística } \\
\text { Desenvolvimento, Sociedade e } \\
\text { Cooperação Internacional }\end{array}$ \\
\hline \multirow{3}{*}{ Sul } & \multirow{3}{*}{9} & Paraná (3) & \multirow{3}{*}{$\begin{array}{c}\text { Instituto de Ciências Básicas da Saúde } \\
\text { Educação } \\
\text { Educação Ambiental } \\
\text { Educação Científica e Tecnológica }\end{array}$} \\
\hline & & Santa Catarina (3) & \\
\hline & & Rio Grande do Sul (3) & \\
\hline
\end{tabular}

mica, política, social, ambiental e cultural dos sujeitos que produzem e reproduzem suas vidas no trabalho com a agricultura, a pesca, o extrativismo, a mineração e outros setores produtivos. Desse modo, torna-se imprescindível que não se pense a educação do campo fora da contradição fundamental entre capital e trabalho e pela nossa opção de classe, sem o objetivo de superação das leis fundamentais do funcionamento da lógica da produção que move o capitalismo: exploração do trabalho e exploração da natureza (Caldart, 2016).

Portanto, torna-se importante considerar que o quantitativo da produção acadêmica nos cursos de LEC só faz sentido se o conjunto de suas ações estiver 
vinculado a uma proposta que coloque a educação escolar e a extraescolar como territórios afinados com um projeto de campo conectado com a agricultura familiar camponesa e com a perspectiva de um projeto societário que aponte para a superação da exploração capitalista da natureza e dos trabalhadores de maneira geral. Observa-se que temas como a participação dos sujeitos coletivos, a agroecologia como sistema produtivo e a questão agrária, mais vinculados à relação escola/campo, estão presentes nas pesquisas produzidas, mas ainda é necessário ampliar esses estudos, compreendendo com maior profundidade os processos de organização e funcionamento dos cursos que têm sido mais capazes de articular formação, projeto de escola, projeto de campo e de sociedade no processo de produção do conhecimento.

Se atualmente o número de instituições de educação superior envolvidas com a educação do campo é sinal promissor da territorialização do tema, é forçoso, por outro lado, examinar as dificuldades surgidas no processo. Vivencia-se nos últimos 15 anos um período de ampliação da esfera pública em direção aos povos camponeses como sujeitos de direitos. Ainda que nesse período as tensões entre agronegócio e agricultura familiar tenham sido acirradas, com notável crescimento do primeiro, pode-se também dizer que aconteceu, em termos históricos, significativo avanço do segundo.

Uma grande resistência a ser construída, que tem nos programas de pós-graduação importantes aliados em sua edificação, diz respeito a se conseguir manter o precioso patrimônio forjado na concepção e na prática das políticas de formação de educadores do campo, fortemente ameaçadas nesse momento. Como muito bem tem alertado Freitas (2012,2013), está em curso um conjunto de políticas que ameaça a educação pública no Brasil e ameaça igualmente a educação do campo. Esse conjunto de políticas que se estrutura no tripé meritocracia-avaliação-padronização objetiva simultaneamente criar as condições para a privatização das escolas públicas que não atingirem os padrões determinados, aumentando o controle ideológico sobre o que e como se ensina nas escolas públicas (Molina, 2015).

Pode-se prever que na conjuntura atual haverá redução, ou até mesmo extinção, de linhas de financiamento para políticas públicas, como o programa de apoio às LECs e o Pronera. Daí a necessidade premente de construir formas para consolidar as conquistas e abrir novas frentes de luta no sentido de ampliar a ocupação do espaço acadêmico.

Os desafios elencados levam-nos para a primeira possibilidade, considerando os dados obtidos neste trabalho. A fortaleza da educação do campo reside em sua materialidade de origem, que consiste em sua vinculação a um projeto de educação, de campo e de sociedade protagonizado pelos camponeses e seus contextos. É no fortalecimento dos princípios da educação do campo que se encontra o caminho possível para as lutas necessárias nos tempos de resistência que se vivencia. Aqui vale acrescentar a articulação, já presente em vários grupos de pesquisa, com instituições e organizações sociais brasileiras e de outros países, visto que o processo de recrudescimento do sistema capitalista é fenômeno que ultrapassa fronteiras.

Em síntese, conta-se com materialidades que sinalizam para a potencialidade de lutas futuras, mas que só farão sentido se mantiverem os princípios que estruturam a educação do campo - articulação entre educação, campo, sociedade e políticas públicas - num processo protagonizado pelos sujeitos camponeses e seus contextos. 


\section{REFERÊNCIAS}

ALBUQUERQUE, J. de O. Crítica à pesquisa em Educação do Campo no Brasil: o limite crítico entre a Educação do Campo e a educação rural. Filosofia e Educação, Campinas, v. 5, n. 2, p. 302-321, out. 2013. https://doi.org/10.20396/rfe.v5i2.8635406 ALMEIDA, A. L. de; CHAMON, E. M. Q. de O. Educação do Campo: o estado da arte de teses produzidas entre 2001 e 2011. In: CONGRESSO INTERNACIONAL INTERDISCIPLINAR EM CIÊNCIAS SOCIAIS E HUMANIDADES, 1., 2012, Niterói. Anais [...]. ANINTER-SH/PPGSD-UFF, 2012.

ANTUNES-ROCHA,M.I.Desafios e perspectivas na formação de educadores: reflexões a partir do curso de Licenciatura em Educação do Campo desenvolvido na FAE/UFMG. In: SOARES, L. et al. (orgs.). Convergências e tensões no campo da formação e do trabalho docente: educação do campo. Belo Horizonte: Autêntica, 2010. p. 389-406.

ANTUNES-ROCHA, M. I.; MARTINS, A. A. Formar docentes para a Educação do Campo: desafios para os movimentos sociais e para a universidade. In: ANTUNESROCHA, M. I.; MARTINS, A. A. (orgs.). Educação do Campo: desafios para a formação de professores. Belo Horizonte: Autêntica, 2009. p. 17-22.

ANTUNES-ROCHA, M. I; RIBEIRO, L. P. Representações sociais em movimento: pesquisas em contextos educativos geradores de mudança. Curitiba: Appris, 2018.

AQUINO, L. V. Representações sociais de educandas e educandos do curso de Licenciatura em Educação do Campo sobre a leitura de textos acadêmicos. 2013. 82f. Dissertação (Mestrado em Educação) - Programa de Pós-Graduação em Educação: Conhecimento e Inclusão Social, Faculdade de Educação, Universidade Federal de Minas Gerais, Belo Horizonte, 2013.

ARAÚJO, A. C. Discursos que revelem o letramento acadêmico na (re)constituição identitária dos educandos da Licenciatura em Educação do Campo. 2016. $143 f$. Dissertação (Mestrado em Linguística) - Universidade de Brasília, Brasília, 2016.

BARBOSA, L. N. S. C. de. Entendimentos a respeito da matemática na Educação do Campo: questões sobre currículo. 2014. 234f. Tese (Doutorado em Educação Matemática) - Instituto de Geociências e Ciências Exatas, Universidade Estadual Paulista "Júlio de Mesquita Filho", Rio Claro, 2014.

BATISTA,J. A. O. Práticas de letramento: cartilhas das minibibliotecas na formação de educadores Kalunga na Licenciatura em Educação do Campo da UnB. 2014. 121f. Dissertação (Mestrado em Educação) - Faculdade de Educação, Universidade de Brasília, Brasília, 2014.

BENFICA, W. A escrita dos educandos(as) em formação para atuação nas escolas do campo na perspectiva das representações sociais. 2017. Tese (Doutorado) - Faculdade de Educação, Programa de Pós-Graduação em Educação: Conhecimento e Inclusão Social, Universidade Federal de Minas Gerais, Belo Horizonte, 2017.

BENTES, E. do S. da S. Os desafios da Licenciatura em Educação do Campo no IFPA Campus de Abaetetuba/PA. 2014. 127f. Dissertação (Mestrado em Serviço Social) - Programa de Pós-Graduação em Serviço Social, Universidade Federal do Pará, Belém, 2014. 
BRITO, M. M. B. O acesso à Educação Superior pelas populações do campo, na universidade pública: um estudo do PRONERA, PROCAMPO e PARFOR, na UFPA. 2013. 131f. Dissertação (Mestrado) - Instituto de Ciências da Educação, Programa de Pós-Graduação em Educação, Universidade Federal do Pará, Belém, 2013. BRITO, M. M. B. Formação de professores na perspectiva da epistemologia da práxis: análise da atuação dos egressos do curso de Licenciatura em Educação do Campo da Universidade de Brasília. 2017. 348f. Tese (Doutorado em Educação) - Universidade de Brasília, Brasília, 2017.

CALAZANS, M. M. As perguntas do professor de Física e a dialética da produção de sentidos na formação de educadores do campo. 2013. 135f. Dissertação (Mestrado em Educação) - Programa de Pós-Graduação em Educação, Conhecimento e Inclusão Social, Faculdade de Educação, Universidade Federal de Minas Gerais, Belo Horizonte, 2013.

CALDART, R. S. Licenciatura em Educação do Campo e projeto formativo: qual o lugar da docência por área. In: MOLINA, M. C.; SÁ, L. M. (orgs.). Licenciatura em Educação do Campo: registros e reflexões a partir das experiências-piloto. Belo Horizonte: Autêntica, 2011. p. 95-122.

CALDART, R. S. Sobre a especificidade da Educação do Campo e os desafios do momento atual. In: FRIGOTTO, G.; CIAVATTA, M. (orgs.). Teoria e educação no labirinto do capital. 4. ed. São Paulo: Expressão Popular, 2016. p. 317-363.

CARVALHO, C. A. da S. Representações sociais das práticas artísticas na atuação de professores do campo. 2018. 328f. (Doutorado em Educação) - Programa de PósGraduação em Educação, Faculdade de Educação, Universidade Federal de Minas Gerais, Belo Horizonte, 2018.

CATANI, A. M.; OLIVEIRA, J. F. de (orgs.). Educação superior e produção do conhecimento: utilitarismo, internacionalização e novo contrato social. Campinas: Mercado de Letras, 2015. (Série Educação Geral, Educação Superior e Formação Continuada do Educador.)

COSTA, F. A.; CARVALHO, H.M. Campesinato. In: CALDART, R. S.; PEREIRA, I. B.; FRIGOTO, G. Dicionário da Educação do Campo. Rio de Janeiro: Expressão Popular, 2012.p. 113-120.

ESMERALDO, G. G. L.; MOLINA, M. C.; ANTUNES-ROCHA, M. I. O fortalecimento da identidade camponesa: repercussões do Programa Nacional de Educação na Reforma Agrária nos estados do Ceará, Minas Gerais e Paraná (19982011). Educação \& Sociedade, Campinas, v. 38, n. 140, p. 569-585, jul./set. 2017. http://dx.doi.org/10.1590/es0101-73302017180449

FERREIRA, M. J. L. Docência na Educação do Campo e formação de educadores: qual o lugar do trabalho coletivo. 2015. 235f. Tese (Doutorado em Educação) Programa de Pós-Graduação em Educação, Universidade de Brasília, Brasília, 2015.

FREITAS, H.C. L. de. Resistências e desafios na formação continuada dos educadores. In: MOLINA, M. C.; MARTINS, M. de F. A. (orgs.). Formação de formadores: reflexões sobre as experiências da Licenciatura em Educação do Campo no Brasil. Belo Horizonte: Autêntica, 2019. p. 397-411. 
FREITAS, L. C. Os reformadores empresariais da educação: da desmoralização do magistério à destruição do sistema público de educação. Educação \& Sociedade, Campinas, v. 33, n. 119, p. 379-404, 2012. http://dx.doi.org/10.1590/S010173302012000200004

FREITAS, L. C. Responsabilização, meritocracia e privatização: conseguiremos escapar ao neotecnicismo? In: PINO, I.; ZAN, D. (orgs.). Plano Nacional da Educação(PNE): questões desafiadoras e embates emblemáticos. Brasília: Inep, 2013. p. 47-84.

FRIGOTTO, G. A interdisciplinaridade como necessidade e como problema nas Ciências Sociais. Ideação, Foz do de Iguaçu, v. 10, n. 1, p. 41-62, 2008.

GHEDINI, C. M. A produção da Educação do Campo no Brasil: das referências históricas à institucionalização. Jundiaí: Paco Editorial, 2017.

GOMES, E. M. Escritas de estudantes da Licenciatura em Educação do Campo da UFVJM: um estudo na perspectiva das representações sociais. 2018. Tese (Doutorado em Educação) - Faculdade de Educação, Programa de Pós-Graduação em Educação: Conhecimento e Inclusão Social, Universidade Federal de Minas Gerais, Belo Horizonte, 2018.

GONÇALVES, T. G. G. L.; HAYASHI, M.C.P.I. Educação do Campo: contribuições para o estado da arte da produção científica (2007-2015). Revista da FAEEBA Educação e Contemporaneidade, Salvador, v. 25, n. 46, p. 207-225, maio/ago. 2016. http://dx.doi.org/10.21879/faeeba2358-0194.2016.v25.n46.p\%25p

INSTITUTO DE PESQUISA ECONÔMICA APLICADA (IPEA). II PNERA: Relatório da II Pesquisa Nacional de Educação em Áreas de Reforma Agrária. Brasília: Ipea, 2015. Disponível em: http://www.ipea.gov.br/portal/images/stories/ PDFs/relatoriopesquisa/150618_relatorio_ii_pesquisa\%20nacional.pdf. Acesso em: 7 ago. 2019.

LEAL, A. A. et al. Cartografia das Licenciaturas em Educação do Campo no Brasil: expansão e institucionalização. In: MOLINA, M. C.; MARTINS, M. F. A. (orgs.). Formação de formadores: reflexões sobre as experiências da Licenciatura em Educação do Campo no Brasil. Belo Horizonte: Autêntica, 2019. p. 39-53.

LIMA, N. L. de. Questões epistêmico-historiográficas sobre a Educação do Campo no Brasil. 2017. Tese (Doutorado em Educação) - Pós-Graduação em Educação, Universidade Federal do Pará, Belém, 2017.

MEDEIROS, E. A. de; DIAS, A. M.I. O estado da arte sobre a pesquisa em Educação do Campo na região Nordeste (1998-2015). Cadernos de Pesquisa, São Luís, v. 22, n. 3, set./dez. 2015. http://dx.doi.org/10.18764/2178-2229.v22.n3.p.115-132

MELO, A. C. C. Sociolinguística: da oralidade à escrita na formação de docentes do campo da área de linguagem. 2018. 106f. Dissertação (Mestrado em Linguística) - Universidade de Brasília, Brasília, 2018.

MOLINA, M.C. Análises de práticas contra-hegemônicas na formação de educadores: reflexões a partir do curso de Licenciatura em Educação do Campo. In: SOUZA, J. V. (org.). O método dialético na pesquisa em educação. Campinas: Autores Associados, 2014. v. 1. p. 263-290. 
MOLINA, M. C. A Educação do Campo e o Enfrentamento das Tendências das Atuais Políticas Públicas. Educacão em Perspectiva, v. 6, n. 2, p. 378-400, 2015. https://doi. org/10.22294/eduper/ppge/ufv.v6i2.665

MOLINA, M. C. Contribuições das Licenciaturas em Educação do Campo para as políticas de formação de educadores. Educação \& Sociedade, Campinas, v. 38, n. 140, p. 587-609, 2017. http://dx.doi.org/10.1590/es0101-73302017181170

MOLINA, M. C. Panorama das Licenciaturas em Educação do Campo nas IES no Brasil. In: RUAS, J. J.; SILVA, C.; BRASIL, A. (orgs.). Educação do Campo: diversidade cultural, socioterritorial, lutas e práticas. São Paulo: Vozes, 2019. (no prelo.) MOLINA, M.C.; ANTUNES-ROCHA,M.I. Educação do Campo: história, práticas e desafios no âmbito das políticas de formação de educadores - reflexões sobre o Pronera e o PROCAMPO. Reflexão e Ação, Santa Cruz do Sul,v. 22, n. 2, p. 220-253, jul./dez. 2014. http://dx.doi.org/10.17058/rea.v22i2.5252

MOLINA, M. C.; HAGE, S. M. Política de formação de educadores do campo no contexto da expansão da Educação Superior. Educação em Questão, Natal, v. 51, n. 37, p. 121-146, jan./abr. 2015.

MOLINA, M.C.; SÁ, L.M. A Licenciatura em Educação do Campo da Universidade de Brasília: estratégias político-pedagógicas na formação de educadores do campo. In: MOLINA, M. C.; SÁ, L. M. (orgs.). Registros e reflexões a partir das experiênciaspiloto (UFMG, UnB, UFBA e UFS). Belo Horizonte: Autêntica, 2011. p. 35-62.

MORAES, V. M. A produção da LEdoC no Brasil: as múltiplas determinações na disputa por projetos societários. 2018. 187f. Tese (Doutorado em Educação) Universidade Tuiuti do Paraná, Curitiba, 2018.

MOURA, A. A. V. A sociolinguística e o seu lugar nos letramentos acadêmicos na formação de professores do campo. 2015. 270f. Tese (Doutorado em Linguística) Programa de Pós-Graduação em Linguística, Universidade de Brasília, Brasília, 2015.

NEVES, L. W. O professor como intelectual estratégico na disseminação da nova pedagogia da hegemonia. In: REUNIÃO NACIONAL DA ANPED, 36., 2013. Anais [...]. Goiânia: UFG, 2013. p. 1-15.

PAITER, L. L. Reflexões sobre a formação docente na área de conhecimento ciências da natureza: a Licenciatura em Educação do Campo - UFSC. 2017. 190f. Dissertação (Mestrado em Educação Científica e Tecnológica) - Universidade Federal de Santa Catarina, Florianópolis, 2017.

PEREIRA, E. N. A prática educativa e as contribuições do processo formativo da organicidade da licenciatura em educação do campo da UnB: um estudo de caso no território Kalunga/Goiás. 2013. 96f. Dissertação (Mestrado em Educação) Universidade de Brasília, Brasília, 2013.

PINTO, T. H. O. A apropriação do discurso científico sobre evolução biológica por futuros professores de ciências em formação no Curso de Licenciatura em Educação do Campo da UFMG. 2013. 103f. Dissertação (Mestrado em Educação) - Programa de Pós-Graduação em Educação, Faculdade de Educação, Universidade Federal de Minas Gerais, Belo Horizonte, 2013. 
PIO, J. V. Apropriação da escrita no contexto da formação de professores de ciências na Educação do Campo. 2011. 106f. Dissertação (Mestrado em Educação) - Programa de Pós-Graduação em Educação, Faculdade de Educação, Universidade Federal de Minas Gerais, Belo Horizonte, 2011.

RIBEIRO, L. P. Representações sociais de educandos do Curso de Licenciatura em Educação do Campo sobre a violência. 2016. 237f. Tese (Doutorado em Educação) - Programa de Pós-Graduação em Educação, Faculdade de Educação, Universidade Federal de Minas Gerais, Belo Horizonte, 2016.

ROMANOWSKI, J. P.; ENS, R.T. As pesquisas denominadas do tipo "estado da arte" em educação. Diálogo Educacional, Curitiba, v. 6, n. 19, p. 37-50, set./dez. 2006.

SANTOS, C. A. A formação de professores para Educação do Campo: estudo epistemológico sobre produção de conhecimento na área. 2016. 80f. Dissertação (Mestrado em Educação) - Programa Pós-Graduação em Educação, Universidade Estadual do Sudoeste da Bahia, Vitória da Conquista, 2016.

SANTOS, C. A. dos. Educação do Campo e políticas públicas no Brasil: a instituição de políticas públicas pelo protagonismo dos movimentos sociais do campo na luta pelo direito à educação. 2009.121f. Dissertação (Mestrado em Educação) - Faculdade de Educação, Universidade de Brasília, Brasília, 2009.

SANTOS, E. M. Contribuições da Licenciatura em Educação do Campo da UNB para práticas educativas contra-hegemônicas na experiência do ProJovem Campo Saberes da Terra do Distrito Federal. 2017. Dissertação (Mestrado em Educação) Universidade de Brasília, Brasília, 2017.

SANTOS, S. P. dos. A concepção de alternância na Licenciatura em Educação do Campo na Universidade de Brasília. 2012. 163f. Dissertação (Mestrado em Educação) - Faculdade de Educação, Universidade de Brasília, Brasília, 2012.

SENRA, R. E. F.; SATO, M. T. Estado da arte da Educação do Campo do Vale do São Lourenço. Cuiabá: PPGE/UFMT, IFMT/Campus São Vicente, 2012.

SILVA, H. do S. de A. Política de formação de educadores do campo e a construção da contra-hegemonia via epistemologia da práxis: análise da experiência da LEdoC/ UFPA-Cametá. 2017. 306f. Tese (Doutorado em Educação) - Programa de PósGraduação em Educação, Instituto de Ciência da Educação, Universidade Federal do Pará, Belém, 2017.

SILVA, M. C. L. e. Caminhos da interdisciplinaridade: da formação por área de conhecimento à prática educativa de egressos da LEdoC - Procampo/IFPA, Campus de Castanhal, PA. 2017. 315f. Tese (Doutorado em Educação) - Programa de PósGraduação em Educação, Universidade Federal do Ceará, Fortaleza, 2017.

SOUZA, M. A. de. Educação do Campo: políticas, práticas pedagógicas e produção científica. Educação \& Sociedade, Campinas, v. 29, n. 105, p. 1089-1111, set./dez. 2008. http://dx.doi.org/10.1590/S0101-73302008000400008

SOUZA, M. A. de. Educação e movimentos sociais do campo: a produção do conhecimento no período de 1987 a 2015. Curitiba: Editora da UFPR, 2015. 
TONÁ, N. Elementos de Reflexão sobre o "Diálogo de Saberes" nas experiências formativas dos movimentos sociais no Paraná. 2008. Monografia (Graduação em Teorias Pedagógicas e Produção do Conhecimento) - Universidade Federal Rural do Rio de Janeiro, Guararema, 2008.

TORRIGLIA, P. L.; DUARTE, N. A ciência e a produção de conhecimento na pesquisa educacional: contribuições de Maria Célia Marcondes de Moraes.Perspectiva, Florianópolis, v. 27, n. 2, p. 347-374, jul./dez. 2009. https://doi.org/10.5007/2175795X.2009v27n2p347

WOORTMANN, K. O modo de produção doméstico em duas perspectivas: CHAYANOV e SAHLINS. In: CARVALHO, H. M. Chayanov e o campesinato. São Paulo: Expressão Popular, 2014. p. 229-272.

\section{SOBRE AS AUTORAS}

Mônica Castagna Molina é doutora em desenvolvimento sustentável pela Universidade de Brasília (UnB). Professora da mesma instituição.

E-mail: mcastagnamolina@gmail.com

Maria Isabel Antunes-Rocha é doutora em educação pela Universidade Federal de Minas Gerais (UFMG). Professora da mesma instituição.

E-mail: isabelantunes@fae.ufmg.br

Maria de Fátima Almeida Martins é doutora em geografia humana pela Universidade de São Paulo (USP). Professora da Universidade Federal de Minas Gerais (UFMG).

E-mail: falmartins.ufmg@gmail.com

Recebido em 25 de março de 2019

Aprovado em 27 de agosto de 2019 